\title{
Cholinergic and cytoprotective signaling cascades mediate the mitigative effect of erythropoietin on acute radiation syndrome
}

\begin{tabular}{|r|l|}
\hline Journal: & Canadian Journal of Physiology and Pharmacology \\
\hline Manuscript ID & cjpp-2017-0578.R1 \\
\hline Date Submitted by the Author: & Article \\
\hline Complete List of Authors: & $\begin{array}{l}\text { Galal, Shereen; National Center for Radiation Research and Technology } \\
\text { (NCRRT), Atomic Energy Authority, Egypt, Health Radiation Research } \\
\text { Abdel-Rafei, Mohamed; National Center for Radiation Research and } \\
\text { Technology (NCRRT), Atomic Energy Authority, Egypt, Radiation Biology; } \\
\text { Hasan, Hesham; National Center for Radiation Research and Technology, } \\
\text { Radiation Biology Department }\end{array}$ \\
\hline Keyword: & $\begin{array}{l}\text { Erythropoietin, acute radiation syndrome, JAK-2, STAT-3, Nrf-2, a-7- } \\
\text { nAChR }\end{array}$ \\
\hline $\begin{array}{r}\text { Is the invited manuscript for } \\
\text { consideration in a Special } \\
\text { Issue?: }\end{array}$ & N/A \\
\hline &
\end{tabular}




\title{
Cholinergic and cytoprotective signaling cascades mediate the mitigative effect of erythropoietin on acute radiation syndrome
}

\author{
Shereen Mohamed Galal ${ }^{1}$, Mohamed Khairy Abdel-Rafei ${ }^{2 *}$ and Hesham Farouk Hasan $^{2}$ \\ ${ }^{1}$ Health Radiation Research Department, National Center for Radiation Research and Technology \\ (NCRRT), Atomic Energy Authority, PO Box 29, Nasr City, Cairo, Egypt. \\ ${ }^{2}$ Radiation Biology Department, National Center for Radiation Research and Technology (NCRRT), \\ Atomic Energy Authority, PO Box 29, Nasr City, Cairo, Egypt.
}

Keywords: Erythropoietin, acute radiation syndrome, JAK-2, STAT-3, Nrf-2, $\alpha-7-n A C h R$

Running title: Erythropoietin counteracts acute radiation syndrome.

*Corresponding author: Dr. Mohamed Khairy Abdel-Rafei, Radiation Biology Department, National Center for Radiation Research and Technology (NCRRT), Atomic Energy Authority, P.O. Box 29, Nasr city, Cairo, Egypt. E-mail: mohamed.marawan2011@yahoo.com. Phone No. +2 0115660996. 


\begin{abstract}
The present investigation aimed to evaluate the radiomitigative efficacy of the recombinant human erythropoietin (rhEPO) against acute radiation syndrome (ARS) in a rat model. Rats were irradiated with a single sublethal dose of $\gamma$ - radiation $\left(7 \mathrm{~Gy}\right.$; total body irradiation; TBI) at the $1^{\text {st }}$ day of experimental course, then received EPO (5000 IU/kg; i.p) 24 hrs post irradiation, rats were observed for 30 days of survival analysis. Administration of EPO improved 30 days survival, alleviated TBIinduced myelosuppression and pancytopenia, by augmenting lymphocytes and WBCs in the peripheral blood of rats, while bone marrow (BM) and spleen cellularity were restored. EPO post exposure treatment alleviated hepatotoxicity biomarkers and restored splenic function. EPO abrogated radiationinduced oxidative stress through the upregulation of the cholinergic anti-inflammatory nicotinic acetylcholine receptor $(\alpha-7-\mathrm{nAChR})$ and the pro-survival janus kinase-2 and signal transducers and activators of transcription JAK-2/STAT-3 signaling mediated via enhancing nuclear factor erythroid-2 related factor-2 (Nrf-2) cytoprotective machinery in liver and spleen of irradiated rats. Moreover, EPO treatment prevented hepatic and splenic apoptosis. In conclusion, the present study establishes the implication of $\alpha$-7-nAChR- JAK-2/STAT-3- Nrf-2 signaling cascade in the radiomitigative potential of EPO against ARS.
\end{abstract}

Key words: Erythropoietin, acute radiation syndrome, JAK-2, STAT-3, Nrf-2, $\alpha-7-n A C h R$

\title{
Introduction
}

Acute radiation syndrome (ARS) is a representative set of symptoms and signals that is deterministically related to the acute whole body exposure to ionizing radiation. Radiation damage results from cell sensitivity to radiation exposure (Jackson et al. 2005). Multi-organ dysfunction (MOD) complicates ARS as manifested by hematopoietic and gastrointestinal subsyndromes indicated by peripheral blood pancytopenia and depletion of bone marrow (BM) progenitor cells (Ghosh et al. 2012) as well as hepatic dysfunction as a highly proliferative sensitive hematopoietic organ (Hossain and Uma Devi 2000). Also, radiation induced oxidative and inflammatory damage might extend to spleen as a radiosensitive secondary hematopoietic organ which results in immune function impairment and lymphoid tissue apoptosis (Bala and Kaur 2015).

It has been previously shown that acetylcholine (ACh) may affect pro-inflammatory and antiinflammatory cytokines. The role of the cholinergic system in radiation-induced inflammatory responses and tissue damage remains unclear (Özyurt et al 2014). ACh is an important neurotransmitter 
that acts on two types of cholinergic receptors: nicotinic and muscarinic receptors (Pappano 2007). The cholinergic anti-inflammatory pathway is a mechanism whereby local inflammation is modulated by the brain via the vagus nerve and nAChRs. $\alpha-7-\mathrm{nAChR}$, a ligand- gated ion channel, mediates the antiinflammatory effects of cholinergic stimulation (Yeboah et al. 2008). The Janus kinase (JAK) family of cytosolic tyrosine kinases, traditionally thought to be coupled to cytokine receptors such as those for the erythropoietin and interleukins, has four members (JAK1, JAK2, JAK3 and TYK2) (Chen et al. 2012). Once activated, JAKs tyrosine phosphorylate and activate other signaling molecules, including the STAT family of nuclear transcription factors after binding of STATs to the receptor (Becerra-Díaz et al. 2011). It is evident that both JAK2 and STAT3 play a pivotal role in anti-apoptotic signaling in the field of myocardial injury (Barry et al. 2007). In addition, it has been demonstrated that Nrf-2, a redox sensitive transcription factor, plays a crucial role in maintaining cell survival mechanisms (Dinkova-Kostova and Abramov 2015). Under oxidative and inflammatory stress, Nrf-2 translocates from cytoplasm to nucleus and promotes expression of downstream cytoprotective enzymes, such as hemeoxygenase- 1(HO-1), NADPH quinone oxidoreductase-1 (NQO-1) and thioredoxin reductase-1 (TRXR-1) that attenuate tissue injury (Loboda et al. 2016).

Erythropoietin (EPO) is a hypoxia- inducible hematopoietic factor, a key protein in erythrocyte production, which is predominantly expressed in the kidney. EPO has multiple protective effects, including antioxidant, anti-inflammatory, angiogenic, and anti-apoptotic effects (Genc et al. 2004). A previous study from Witthuhn et al. demonstrated that EPO could induce tyrosine phosphorylation of JAK2 kinase in vitro (Witthuhn et al. 1993). There is vast and proved evidence that erythropoietin receptor (EPOR) is expressed in non-hematopoietic tissues (Arcasoy 2010), such as liver and spleen (David et al. 2005; Gammella et al. 2015). Therefore, the present investigation was conducted to test whether EPO could mitigate the deleterious response elicited by TBI associated MOD and ARS with special emphasis liver and spleen as highly radiosensitive vital organs. Moreover, the implication of $\alpha$ 7-nAChR- JAK-2/STAT-3- Nrf-2 signaling cascade in the cytoprotective efficacy of EPO against ARS. 


\section{Materials and methods}

\section{Chemicals and drugs}

Erythropoietin was purchased as alpha rhEPO 4000 IU ampoules (Epotein) from SEDICO, Egypt. Pyrogen free $0.9 \%$ isotonic saline $(0.9 \% \mathrm{NaCl})$ from Otsuka Pharmaceuticals. Phosphate buffer saline (PBS), Ethylene diaminetetracetic acid (EDTA) and all of the remaining chemicals used in this study were of the highest quality and analytical grade. Antibodies against JAK-2, p-JAK-2, STAT-3, pSTAT-3, $\alpha-7-$ nAChR and $\beta$ - actin were obtained from Santa Cruz Biotechnology ((Santa Cruz, California, USA).

\section{Experimental animals}

Male albino rats (140-150g); 6 weeks old obtained from the Egyptian Holding Company for Biological Products and Vaccines were used as experimental animals. Animals were housed in the appropriate cages and maintained in good ventilation, at a temperature of $25{ }^{\circ} \mathrm{C} \pm 5{ }^{\circ} \mathrm{C}, 60 \%$ humidity, with suitable illumination conditions (normal light-dark cycle), and were provided with a standard pellet diet and fresh water ad libitum for the duration of the experimental period. The animals were left to acclimatize to the lab environment for one week before starting the experiments.

\section{Ethics statement}

Animal procedures were performed in accordance with the recommendations in the Guide for the Care and Use of Laboratory Animals (Eighth Edition, 2011, published by The National Academies Press, 2101 Constitution Ave. NW, Washington, DC 20055, USA) and under regulations of Animal Care and Use of NCRRT in Egypt. All efforts were made to minimize animal suffering. All sampling was performed under light ether anesthesia.

\section{Radiation facility and irradiation procedures}

Irradiation (R) was performed at NCRRT, Cairo, Egypt, using Gamma Cell - 40 ( ${ }^{137}$ Cesium), biological irradiator manufactured by Canada Ltd. Ottawa, Ontario, Canada. Animals were placed in plastic sample tray with lid and supports provided for use in the sample cavity. The unit has ventilation holes which align with ventilation parts through the main shield to provide a means for uniform irradiation for small animals. Rats were whole body exposed to doses of gamma radiation (7 Gy on the $1^{\text {st }}$ day of experimental course) given at a dose rate of $0.641 \mathrm{~Gy} / \mathrm{min}$ at the time of experiment, calculated according the dosimeter department at NCRRT. 


\section{Experimental design and treatment protocol}

Eighty rats were randomly categorized into four groups as follows: Group I (control group; C) were normal rats that were intraperitoneally (i.p.) administered the vehicle at corresponding volumes (serum albumin $2.5 \mathrm{mg} / \mathrm{ml}$ in isotonic saline solution $0.9 \% ; 2 \mathrm{ml} / \mathrm{Kg}$ ) at corresponding times; Group II (irradiated group; R) were the rats to which we administered the vehicle at the corresponding volume (serum albumin $2.5 \mathrm{mg} / \mathrm{ml}$ in isotonic saline solution $0.9 \%$; total volume of $2 \mathrm{ml} / \mathrm{Kg}$ body mass) 24 hours post irradiation with sublethal TBI 7 Gy (Venkateswaran et al. 2016) at the $1^{\text {st }}$ day of experimental course; Group III (erythropoietin group; EPO) were rats received a single i.p. injection at a dose of (5000 IU/Kg body mass; i.p.) of EPO (Elshiekh et al. 2015) reconstituted in $2 \mathrm{ml} / \mathrm{Kg}$ body mass of vehicle, Group IV (irradiated erythropoietin treated; EPO+ R) were rats exposed to sublethal irradiation $(7 \mathrm{~Gy}$ ) and received EPO at 24 hours post irradiation. Animals were observed and monitored for 30 days for radiation sickness symptoms and mortality recording, these data were expressed as percentage of survival and body weights were recorded weekly along 4 weeks at specific time points. At the end of the experimental period (30 days), the survived rats were sacrificed under gentle diethyl ether anesthesia prior to blood, liver and spleen collection. Liver and spleen were dissected out and weighed to calculate liver and spleen weights to body weight ratios.

\section{Survival analysis and radiation sickness}

To determine the radiomitigative effect of EPO against sublethal TBI, the survival rate of rats for 30 days was investigated and data were expressed as survival percentage (Jothy et al. 2016). Mortalities time points were recorded and animals were thoroughly observed for clinical visual observations included signs of illness, epilation, alterations in skin and fur, irritability and behavioral patterns.

\section{Body mass and liver/spleen mass index}

Body weights were recorded at the beginning of each week for 4 weeks during the morning using a digital balance. After animal sacrifice, livers were carefully excised and weighed for the evaluation of their body/liver or spleen mass ratios. The ratio was calculated using the following equation (Al-Attar and Zari 2010):

Liver/spleen mass index $(\%)=$ Liver/spleen mass $(\mathrm{g}) /$ Body mass $(\mathrm{g}) \times 100$

\section{Hematological studies}

For peripheral haematological analysis, blood was drawn from the retro- orbital venous plexus at days 3, 7, 15 and 30 post irradiation for studying the hematopoietic and myelotoxic effects of sublethal irradiation. Blood wad divided into two vials, one containing $0.5 \mathrm{M}$ EDTA was used as an anticoagulant to investigate erythrocytic count (RBCs), haemoglobin content $(\mathrm{Hb})$, hematocrit \% (Hct), platelet count (PLT) and total as well as differential leucocytic count (WBCs) were determined by 
Swelab alpha auto hematological counter according to the method of Dacie and Lewis (2001). Blood smears were prepared as soon as possible after blood collection on glass slide and quickly dried and stained with Leishman's stain for differential blood count.

\section{Tissue collection and preparation}

For the different biochemical measurements, blood samples were collected and allowed to stand for 30 $\min$ at $37{ }^{\circ} \mathrm{C}$, and then centrifuged at $3000 \mathrm{~g}$ for $15 \mathrm{~min}$ at $4{ }^{\circ} \mathrm{C}$ to separate sera, and then were stored at $-70{ }^{\circ} \mathrm{C}$ for the determination of hepatotoxicity parameters such as the levels of aspartate aminotransferase (AST), alanine aminotransferase (ALT), glutamate dehydrogenase (GLDH) as a prominent marker of hepatic injury (Jaeschke and McGill 2013) and caspase- cleaved cytokeratin- 18 M30 (CK-18 M30) which is an epithelial cell- specific filament released into circulation during cell death, an outstanding marker of hepatic apoptosis (Wei et al. 2017). Also, interleukin-10 (IL-10) was estimated in serum as an indicator for splenic function (Hassan et al. 2014). The liver and spleen tissues were quickly harvested, and one part of the liver and spleen tissues was instantly fixed in 10\% phosphate-buffered formaldehyde for histological examination. The remaining portion of the excised hepatic lobe and spleen was divided into 2 separate pieces for different biochemical assessments. To this end, the first part was homogenized in 10 volumes of ice-cold phosphate buffer $\left(100 \mathrm{mmol} \cdot \mathrm{L}^{-1}, \mathrm{pH}\right.$ 7.4) to determine oxidative stress markers (malondialdehyde; MDA and nitric oxide; NOx) and the cellular proliferation marker (arginase activity). The second portion of the liver and spleen was subdivided into 2 equal portions: for reverse transcription PCR analysis, the first portion of hepatic lobules $(250 \mathrm{mg})$ and spleen were homogenized in lysis buffer $\left(200 \mathrm{mmol} \cdot \mathrm{L}^{-1} \mathrm{NaCl}, 5 \mathrm{mmol} \cdot \mathrm{L}^{-1}\right.$ EDTA, $10 \mathrm{mmol} \cdot \mathrm{L}^{-1}$ Tris, $10 \%$ glycerine, $1 \mathrm{mmol} \cdot \mathrm{L}^{-1} \mathrm{PMSF}, 1 \mathrm{mg} \cdot \mathrm{mL}^{-1}$ leupeptin, and $28 \mathrm{mg} \cdot \mathrm{mL}^{-1}$ aprotinin; pH 7.4) (Sigma-Aldrich) for assessment of the gene expression redox sensitive antioxidant machinery (Nrf-2, HO-1, NQO-1, TRXR-1) and apoptotic markers (Bcl-2 associated X protein; Bax, B- cell lymphoma-2; Bcl-2, p53) in liver and spleen. For protein expression using Western immunoblotting analysis, the second portion of the liver and spleen was homogenized in homogenizing buffer $\left(20 \mathrm{mmol} \cdot \mathrm{L}^{-1}\right.$ Tris- $\mathrm{HCl}(\mathrm{pH} 7.4), 2 \mathrm{mmol} \cdot \mathrm{L}^{-1}$ EGTA, $5 \mathrm{mmol} \cdot \mathrm{L}^{-1}$ EDTA, $1.5 \mathrm{mmol} \cdot \mathrm{L}^{-1}$ pepstatin, $2 \mathrm{mmol} \cdot \mathrm{L}^{-1}$ leupeptin, $0.5 \mathrm{mmol} \cdot \mathrm{L}^{-1}$ phenylmethylsulfonyl fluoride $(\mathrm{PMSF}), 0.2 \mathrm{U} \cdot \mathrm{mL}^{-1}$ aprotinin, and $2 \mathrm{mmol} \cdot \mathrm{L}^{-1}$ dithiothreitol; Sigma-Aldrich), using a Polytron homogenizer. Cells were washed twice with ice-cold PBS and lysed in lysis buffer $\left(0.5 \% \mathrm{NP}-40,50 \mathrm{mmol} \cdot \mathrm{L}^{-1}\right.$ Tris- $\mathrm{HCl}(\mathrm{pH}$ 8.0), $100 \mathrm{mmol} \cdot \mathrm{L}^{-1} \mathrm{NaCl}, 1 \mathrm{mmol} \cdot \mathrm{L}^{-1} \mathrm{PMSF}, 1 \mathrm{mmol} \cdot \mathrm{L}^{-1}$ sodium orthovanadate, $10 \mathrm{mg} \cdot \mathrm{mL}^{-1}$ aprotinin, and $10 \mathrm{mg} \cdot \mathrm{mL}^{-1}$ leupeptin) for 20-30 min on ice, for the evaluation of JAK-2, p-JAK-2 $\left(\mathrm{Tyr}^{1007 / 1008}\right)$, STAT-3, p-STAT-3 (Tyr ${ }^{705}$ ) and $\left.\alpha-7-\mathrm{nAChR}\right)$ in liver and spleen. 


\section{Biochemical Assay}

\section{Serum biochemical tests}

The collected sera were used for the colorimetric estimation of AST and ALT as previously described (Reitman and Frankel 1957), by measuring the amount of pyruvate or oxaloacetate produced by forming 2, 4-dinitrophenylhydrazone. The color produced was measured spectrophotometerically at $546 \mathrm{~nm}$ using the commercial kits purchased from Biodiagnostic (Dokki, Giza, Egypt). Serum levels of GLDH and CK-18 M30 were measured using a corresponding commercial immunoassay of rat GLDH ELISA kit (Elabscience, USA) and rat CK-18 ELISA kit (MyBiosource, San Diego, CA, USA) according to the manufacturers' instructions. GLDH and CK-18 M30 were expressed as $\mu \mathrm{IU} / \mathrm{ml}$ and $\mathrm{mIU} / \mathrm{ml}$, respectively. Serum IL-10 level was determined using a commercial rat IL-10 ELISA kit (Quantikine, R\&D systems, Minneapolis, Minnesota, USA) according to the manufacturers' instructions. IL-10 levels are expressed in pg/ml.

\section{Liver and spleen tissue biochemical measurements}

In liver and spleen tissues' homogenates, thiobarbituric acid reactive substances (TBARS), represented by MDA as an index for lipid peroxidation, were used to determine oxidative damage, following the method of Lefevre et al. (1998). Briefly, 0.8\% TBA (1.5 ml), 8.1\% SDS (200 $\mu \mathrm{l}), 20 \%$ acetic acid (1.5 $\mathrm{ml})$ and distilled water $(600 \mu \mathrm{l})$ were added to $200 \mu \mathrm{l}$ tissue homogenate at temperature of $95^{\circ} \mathrm{C}$ for 30 min and immediately cooled on ice to form colored product. The resultant pink color was a representative of TBARS and was measured colorimetrically at $534 \mathrm{~nm}$ using a spectrophotometer. In addition, hepatic and splenic NO levels were estimated indirectly as nitrite/nitrate concentrations according to the method of Miranda et al. (2001), where vanadium trichloride was used to reduce nitrate into nitrite. The pink azo-dye produced by the reaction of nitrite with sulfanilic acid, followed by the subsequent coupling with $N$-(1-naphthyl)-ethylenediamine was measured colorimetrically at 540 $\mathrm{nm}$, and NOx is expressed in micromoles per milligram of protein. Arginase activity was measured using a colorimetric assay kit (Sigma-Aldrich, St. Louise, MO). Arginase activity was defined as the amount of enzyme that catalyzes $1 \mu \mathrm{mol}$ of urea $/ \mathrm{min} / \mathrm{mg}$ protein at $37^{\circ} \mathrm{C}$. Moreover, caspase- 3 activity was estimated according to the manufacturer's instructions using the ELISA Kit (Cusabio Biotech Co., China).

Detecting the gene expression of Nrf-2, HO-1, NQO-1, TRXR-1, Bax, Bcl-2 and p53 using RTPCR

\section{$R N A$ isolation and reverse transcription}

RNA was extracted from the liver and spleen tissues homogenate, using the RNeasy plus minikit (QIAGEN, Venlo, the Netherlands), according to the manufacturers' instructions. Genomic DNA was 
eliminated with a DNase-on-column treatment, which was supplied with the kit. The RNA concentration was determine spectrophotometrically at $260 \mathrm{~nm}$ using the NanoDrop ND-1000 spectrophotometer (Thermo Fisher Scientific, Waltham, Mass.), and RNA purity was checked by means of the absorbance ratio at 260/280 nm. RNA (1 $\mu \mathrm{g})$ was used in the subsequent cDNA synthesis reaction, which was performed using the Reverse Transcription System (Promega, Leiden, the Netherlands). Total RNA was incubated at $70{ }^{\circ} \mathrm{C}$ for $10 \mathrm{~min}$ to prevent secondary structures. The RNA was supplemented with $\mathrm{MgCl} 2\left(25 \mathrm{mmol} \cdot \mathrm{L}^{-1}\right)$, RTase buffer $(10 \times)$, dNTP mixture $\left(10 \mathrm{mmol} \cdot \mathrm{L}^{-1}\right)$, oligod $(\mathrm{t})$ primers, RNase inhibitor $(20 \mathrm{U})$, and AMV reverse transcriptase $\left(20 \mathrm{U} \cdot \mu \mathrm{L}^{-1}\right)$. This mixture was incubated at $42{ }^{\circ} \mathrm{C}$ for $1 \mathrm{~h}$.

Quantitative real-time PCR

qRT-PCR was performed in an optical 96-well plate with an ABI PRISM 7500 fast sequence detection system (Applied Biosystems, Carlsbad, Calif.) and universal cycling conditions of 40 cycles of $15 \mathrm{~s}$ at $95{ }^{\circ} \mathrm{C}$ and $60 \mathrm{~s}$ at $60{ }^{\circ} \mathrm{C}$ after an initial denaturation step at $95^{\circ} \mathrm{C}$ for $10 \mathrm{~min}$. Each $10 \mu \mathrm{L}$ reaction contained $5 \mu \mathrm{L}$ SYBR Green Master Mix (Applied Biosystems), $0.3 \mu \mathrm{L}$ gene-specific forward and reverse primers $\left(10 \mu \mathrm{mol} . \mathrm{L}^{-1}\right), 2.5 \mu \mathrm{L}$ cDNA, and $1.9 \mu \mathrm{L}$ nuclease free water. The sequences of PCR primer pairs used for each gene are shown in Table 1. Data were analyzed with the ABI Prism sequence detection system software and quantified using the v1.7 Sequence Detection Software from PE Biosystems (Foster City, Calif.). Relative expression of the studied genes was calculated using the comparative threshold cycle $\left(2^{-\Delta \Delta \mathrm{CT}}\right)$ method. All of the values were normalized to the endogenous control, $\beta$-actin (Livak and Schmittgen 2001).

Table (1)

\section{Detection of JAK-2, p-JAK-2, STAT-3, p-STAT-3 and $\alpha$-7- nAChR by western blot analysis}

Liver and spleen tissues' homogenates were prepared for Western blotting as previously described by Omar et al. (2009) using homogenization lysis buffer (Sigma-Aldrich). The tissue lysate was centrifuged at $8678 \mathrm{~g}$ for $20 \mathrm{~min}$ at $4{ }^{\circ} \mathrm{C}$. The lysate was then collected, and protein concentration was determined with a BCA protein assay kit (Thermo Fisher Scientific). Aliquots of $7.5 \mu \mathrm{g}$ protein from each sample were denatured, then each sample was loaded onto 8\% sodium dodecyl sulphate polyacrylamide gel electrophoresis (SDS-PAGE) and transferred to a nitrocellulose membrane (Amersham Bioscience, Piscataway, New Jersey, USA) using a semidry transfer apparatus (Bio-Rad, Hercules, Calif.). The membranes were incubated with 5\% milk blocking buffer containing 10 mmol. $\mathrm{L}^{-}$ ${ }^{1}$ Tris- $\mathrm{HCl}$ (pH 7.4), 150 mmol.L ${ }^{-1} \mathrm{NaCl}$, and Tris-buffered saline with $0.05 \%$ Tween-20 (TBST) at 4 ${ }^{\circ} \mathrm{C}$, overnight. The membranes were then washed with TBST and incubated with a 1:1000 dilution of anti- JAK-2, anti-p-JAK-2 (Tyr $\left.{ }^{1007 / 1008}\right)$, anti-STAT-3, anti-p-STAT-3 $\left(\right.$ Tyr $\left.^{705}\right)$ and anti- $\alpha-7-n A C h R$ 
antibodies for overnight on a roller shaker at $4{ }^{\circ} \mathrm{C}$. Immunoblotting was done with the indicated primary antibody followed by the appropriate horseradish peroxidase (HRP)-conjugated goat immunoglobulin (Amersham Biociences). Chemiluminescence detection was performed with the Amersham detection kit, according to the manufacturer's protocols, and exposed to X-ray film. Protein levels were quantified by densitometric analysis of the auto-radiograms using a scanning laser densitometer (Biomed Instruments). Results were determined after normalization for $\beta$-actin protein expression (as the housekeeping protein) (Mingone et al. 2003).

\section{Histopathological examination}

Autopsy samples from the livers and spleens of the rats in different groups were harvested and fixed in $10 \%$ formol saline for $24 \mathrm{~h}$. The samples were washed with tap water, and then serial dilutions of alcohol (methyl, ethyl, and absolute ethyl) were used for dehydration. The specimens were cleared in xylene and embedded in paraffin at $56^{\circ} \mathrm{C}$ in a hot-air oven for $24 \mathrm{~h}$. Paraffin-bees wax tissue blocks were prepared for sectioning at a thickness of $4 \mu \mathrm{m}$ using a slide microtome. The tissue sections were then collected onto glass slides, de-paraffinized, and stained with hematoxylin and eosin (H\&E). The preparations obtained were visualized using a Nikon microscope at a magnification of $\times 400$ (Banchroft et al. 1996).

\section{Statistical analysis}

The data are the mean \pm SEM. Statistical analysis was done using one-way analysis of variance (ANOVA), followed by a Tukey- Kramer post-hoc multiple comparisons test among treatment means. Survival studies' data were analyzed using the Kaplan-Meier method followed by Mantel-Cox (logrank) and Gehan-Breslow-Wilcoxon tests for assessment of significant differences. Values for $P<0.05$ were considered statistically significant. All analyses were estimated using SPSS software, version 21. Based on sample size calculation by ANOVA, experimental design allows detecting the difference between groups ranging from 35-40\% with a SD 25\% of mean and power $(\beta)$ required to detect a difference of a similar magnitude to that observed at 30 days (observed effect size of 1.2 for single sublethal 7 Gy) was estimated by a post hoc power calculation with the lowest sample size ( $N=20$ / group) has a $\beta=0.8$ to detect an effect of 1 with an error $\alpha=0.05$. 


\section{Results}

\section{EPO post-exposure treatment in rats improved 30 days survival and attenuated radiation sickness signs after TBI}

The vehicle- treated irradiated rats ( $\mathrm{R}$ group) exhibited typical signs of radiation sickness such as reduced food and water intake, mild local skin reactions including dermal erythma and depilation, irritability followed by lethargy, ruffling of hair, emaciation, diarrhea accompanied by tarry stool and facial edema were observed 3 days post-irradiation. Survival analysis showed a significant difference $(\mathrm{P}<0.0001)$ in survival time among groups. In addition, Kaplan-meier survival plot indicated that the first death event has occurred on day 5 with a median survival rate on day 20 following irradiation in $\mathrm{R}$ group (Fig 1 A). Moreover, R group showed only 30\% (6 out of 20 rats) survival on the last day of survival analysis (day 30) (Fig 1 A). On the other hand, EPO+R had reduced signs of radiation sickness and extended survival rates by $35 \%$ over the vehicle- treated $\mathrm{R}$ group with the overall survival rates of $65 \%$ (13 out of 20 rats) at the end of the survival analysis (Fig 1 A). Notably, EPO+R delayed the onset of radiation- induced mortality to be recorded on day 13 (Fig 1 A) as compared to R group, suggesting the prolonged survival rates and confirming the radiomitigative efficacy of EPO. The Mantel- Cox (log rank) and Gehan- Breslow- Wilcoxon statistics indicated that the survival curves were significantly different $(\mathrm{P}<0.0001)$ among treated groups. All animals in control and EPO groups were survived until the end of experimental period with 100\% survival rates (Fig 1 B) and displayed no signs of toxicity during the survival test.

\section{Fig 1.}

\section{Effect of EPO post- exposure treatment on body weight changes and organ indices after TBI}

Total body weight was measured at the beginning and the end of the experimental course (Fig 2 A). Results in Fig 2A\&B indicated no significant change in mean body weight between control and EPOtreated normal rats. The percent change in body weight between the initial and final weights showed a significant decline $(\mathrm{P}<0.05)$ as shown in $\mathrm{R}$ group when compared to the corresponding control (Fig 2 B). In R group, the body weight loss started at the first week post-irradiation and continued till it reach the maximum body weight loss percentage at the $4^{\text {th }}$ week after TBI and recorded 8.23 and $23 \%$ weight loss at the $1^{\text {st }}$ and $4^{\text {th }}$ weeks, respectively (Fig 2 B). On the other hand, EPO $+\mathrm{R}$ reduced the body weight loss and substantially ameliorated $(\mathrm{P}<0.05)$ the percent change in body weight compared to $\mathrm{R}$ sole treatment (Fig 2 A\& B). The ratio between the liver weights to the total body weight revealed a significant increase $(\mathrm{P}<0.05)$ in $\mathrm{R}$ group compared to the control set and exhibited $161.1 \%$ change in 
the liver weight (Fig 2 C). Contrariwise, the ratio of spleen weight to the total body weight exhibited a remarkable reduction $(\mathrm{P}<0.05)$ in $\mathrm{R}$ group as compared to the control set with a percent change of 47.2 (Fig 2 D). Upon EPO post- exposure administration to irradiated rats (EPO+ R), the radiation- induced alterations in the organ indices were significantly reversed $(\mathrm{P}<0.05)$ as depicted in Fig 2 C\&D. Whereas, there were no significant changes in liver and spleen weights in EPO treated non-irradiated rats when compared to their respective controls (Fig 2 C\&D).

\section{Fig 2.}

\section{EPO post- exposure treatment augmented BM and spleen cellularity after TBI}

Bone marrow $(\mathrm{BM})$ and spleen are the most radiosensitive hematopoietic and lymphoid organs. To evaluate the radiomitigative potential of EPO sub-lethal TBI, BM and spleenocytes viability were assessed. Exposure of rats to sub-lethal TBI resulted in a significant decrease $(\mathrm{P}<0.05)$ in $\mathrm{BM}$ and spleenocytes viability when compared to control rats (Fig 3). However, accelerated BM and spleenocytes reconstitution was observed in $\mathrm{EPO}+\mathrm{R}$ group showing significant elevation $(\mathrm{P}<0.05)$ above the R group (Fig 3). Worthwhile, no significant change was recorded in EPO group when compared to the control set.

\section{Fig 3.}

\section{EPO post- exposure treatment replenishes hematological compartments of irradiated rats}

Fig (4) discerned no significant change in the peripheral blood compartments (RBCs, WBCs, Hb, and HCT) in EPO group as compared to control. Irradiation of rats at sub-lethal dose induced a significant depression $(\mathrm{P}<0.05)$ in RBCs, WBCs, and PLT count and Hb content as well as HCT \% in R group compared to the respective control. This decline in the hematological indices was obvious at $3^{\text {rd }}$ and $7^{\text {th }}$ days post-irradiation and continued until the end of the experimental course at the day $30^{\text {th }}$ when compared to the corresponding control. This reduction in the hematological indices was significantly replenished $(\mathrm{P}<0.05)$ in EPO+ R group when compared to R group. Noticeably, EPO post- exposure treatment in irradiated rats achieved a remarkable restoration in RBCs and PLT count as well as Hb content on day $30^{\text {th }}$ with values comparable to those of the control set, which implies the potential hematopoietic efficacy of EPO against radiation- induced hematological collapse.

Fig 4. 


\section{Impact of EPO post- exposure treatment on leukocyte differential of irradiated rats}

Administration of EPO to normal non-irradiated rats resulted in non- significant change in leukocyte differential when compared to control rats. Exposure of rats to TBI single sub-lethal fraction at 7 Gy markedly diminished $(\mathrm{P}<0.05)$ lymphocytes, monocytes, neutrophils, and eosinophils percentage at $3^{\text {rd }}$ and $7^{\text {th }}$ days post-irradiation and continued until the last day of the experimental period ( $30^{\text {th }}$ day) in $\mathrm{R}$ group as compared to control (Fig 5). In EPO+ R group, EPO treatment significantly restored (P< 0.05) lymphocytes percentage and normalized monocytes, neutrophils and eosinophils percentages to reach nearly the control values as compared to $\mathrm{R}$ group rats (Fig 5). This recovery in leukocyte population in EPO+ R group indicates that EPO counteracts radiation- induced myelosuppression.

Fig 5.

\section{EPO post- exposure treatment improved hepatotoxicity profile of irradiated rats}

Figure 6 depicted no significant change in the hepatotoxicity biomarkers (AST, ALT, GLDH, and CK$18 \mathrm{M} 30)$ in EPO group as compared to control (Fig $6 \mathrm{~A}-\mathrm{C})$. On the other hand, irradiation of rats induced a significant increase $(\mathrm{P}<0.05)$ in serum AST, ALT activities (Fig 6 A) as well as GLDH and CK-18 M30 levels (Fig 6 B\& C) when compared to the control set. Whereas, EPO+ R group revealed a marked amelioration $(\mathrm{P}<0.05)$ in the aforementioned parameters as compared to R group (Fig 6 A- C). Moreover, liver sections from the control and EPO group showed that normal architecture of the hepatic lobule was preserved (Fig 6 D; C\& EPO). On the other hand, total body irradiation of rats (7 Gy) caused a sever histological degeneration in the hepatic architecture as represented by sever dilatation and congestion in the portal vein as observed in the portal area associated with multiple numbers of newly formed bile ductules as well as periductal fibrosis while the parenchyma showed degenerative change in the hepatocytes (Fig $6 \mathrm{D}$; R). Administration of EPO $24 \mathrm{hr}$ post TBI to rats diminished pathological alterations induced by TBI as revealed by the observation of a subtle degree of vacuolar degeneration and moderately dilated central vein accompanied with milder degree of central vein congestion and noticeable absence of periductal fibrosis and parenchymal degeneration (Fig 6 D; $\mathrm{EPO}+\mathrm{R})$.

Fig 6. 


\section{EPO post- exposure treatment curbs radiation- induced MOD after TBI}

To demonstrate the radiomitigative potential of EPO post- exposure treatment against MOD in TBI rat model, the cholinergic anti-inflammatory and cytoprotective molecular signaling pathways were evaluated in liver and spleen of irradiated rats.

Enhancement of $\alpha-7-$ nAChR expression mediated JAK-2/STAT-3/Nrf-2/HO-1 signaling axis activation upon EPO administration in liver and spleen of irradiated rats

To elucidate the transcriptional activation of the pro-survival molecular signaling JAK-2/STAT-3 and its downstream cytoprotective molecular targets $\mathrm{Nrf}-2$ / HO-1 cascades as well as the implication of the cholinergic anti-inflammatory $\alpha-7-n A C h R$ subunit in the liver and spleen of irradiated rats upon EPO post- exposure treatment, their expression was tested. In EPO group, a significant up-regulation $(\mathrm{P}<$ 0.05) in $\alpha-7$ - nAChR, p- JAK-2, and p- STAT-3 protein expression as well as Nrf-2 and HO-1 mRNA levels was observed in hepatic and splenic tissues as compared to normal control group (Fig 7 A-G\& Fig 8). Irradiation of rats induced a significant down-regulation $(\mathrm{P}<0.05)$ in $\alpha-7-\mathrm{nAChR}, \mathrm{p}-\mathrm{JAK}-2$, and p- STAT-3 protein expression as well as Nrf-2 and HO-1 mRNA levels in hepatic and splenic tissues as revealed in R group when compared to EPO group and control animals (Fig 7 A- G\& Fig 8). Interestingly, EPO + R significantly enhanced $(\mathrm{P}<0.05) \alpha-7$ - nAChR, p- JAK-2, and p- STAT-3 hepatic and splenic protein expression when compared to R group (Fig 7 A- G). Consequently, hepatic and splenic Nrf-2 and HO-1 mRNA levels showed a significant elevation $(\mathrm{P}<0.05)$ in $\mathrm{EPO}+\mathrm{R}$ group as compared to R group set (Fig 8), suggesting the stimulation of hepatic and splenic JAK-2/STAT-3/Nrf2/HO-1 signaling axis mediated via $\alpha-7-\mathrm{nAChR}$ stimulation following EPO post- exposure treatment in irradiated rats.

Fig 7.

Fig 8.

EPO post- exposure treatment abolishes oxidative stress, boosts Nrf-2 driven phase II antioxidant enzymes and retrieves splenic immune function of irradiated rats

To further elaborate the reason that EPO administered at 24 hours post- irradiation afforded hepatic and splenic protection against radiation- induced oxidative damage, we next explored the underlying mechanism. Hence, we assumed that EPO might activate Nrf-2- antioxidant responsive elements (ARE). Next, we evaluated the expression of ARE- mediated genes (NQO-1 and TRXR-1) to determine whether EPO could regulate the endogenous antioxidant system in liver and spleen of TBI rats. Fig 9 showed that administration of EPO to non-irradiated rats significantly enhanced $(\mathrm{P}<0.05)$ 
NQO-1 and TRXR-1 gene expression and recorded 3.6 and 3.2 fold changes in the liver tissue, respectively and 2.7 and 2.5 fold changes in the spleen tissue, respectively when compared to the respective control (Fig 9 A). Expectedly, irradiation of rats (R group) resulted in a substantial reduction $(\mathrm{P}<0.05)$ in NQO-1 and TRXR-1 expression by 55 and $64 \%$, respectively in the liver tissue as well as 53 and $66 \%$, respectively in the spleen as compared to the control group (Fig 9 A). However, a remarkable elevation $(\mathrm{P}<0.05)$ was observed in MDA and NO levels (Fig $9 \mathrm{~B} \& \mathrm{C})$ paralleled by a significant reduction $(\mathrm{P}<0.05)$ in arginase activity and IL-10 serum level (Fig $9 \mathrm{D} \& \mathrm{E})$ in $\mathrm{R}$ group as compared to the control set. Contrariwise, EPO $+\mathrm{R}$ significantly upregulated $(\mathrm{P}<0.05) \mathrm{NQO}-1$ and TRXR-1 gene expression by 6.4 and 7.3 fold changes, respectively in the hepatic tissue as well as a fold changes of 4.6 and 6.5, respectively in the splenic tissue when compared to R group (Fig 9 A). Moreover, MDA and NO levels were significantly diminished $(\mathrm{P}<0.05)$ accompanied by a significant rise $(\mathrm{P}<0.05)$ in arginase activity and IL-10 level were noted in EPO+ $\mathrm{R}$ group as compared to $\mathrm{R}$ group (Fig 9 B-E), suggesting the restoration of redox balance through the upregulation of phase II antioxidant enzymes expression and arginase activity. In the same line, EPO post exposure treatment $(\mathrm{EPO}+\mathrm{R})$ improved splenic histological architecture and restored spleenocytes and splenic cellular matrix against splenic depopulation induced by R (Fig 9 F).

Fig 9.

\section{EPO post- exposure treatment downregulates pro-apoptotic genes (Bax and p53) with restoration} of anti-apoptotic Bcl-2 expression in liver and spleen of TBI rats

Total body irradiation of rats instigated apoptosis in liver and spleen as indicated by a 3.4 and 3.7 fold increase in Bax mRNA expression, respectively paralleled by a 2.7 and 3.2 fold elevation, respectively in caspase-3 activity, as a reliable apoptotic marker (Fig 10 A\& C). However, hepatic p53 mRNA expression showed non-significant change between all groups and revealed a pronounced rise $(\mathrm{P}<0.05)$ in splenic p53 expression in R group as compared to control rats (Fig $10 \mathrm{~A}$ ). On contrary, the antiapoptotic Bcl-2 mRNA levels were significantly diminished $(\mathrm{P}<0.05)$ in hepatic and splenic tissues of untreated irradiated animals as compared to normal rats (Fig 10 A). Surprisingly, EPO post- exposure treatment of irradiated rats as in EPO $+\mathrm{R}$ group counteracted these changes in favor of cell survival (Fig 10 A-C). Moreover, EPO+ R recovered the balance between the pro-apoptotic Bax expression and the anti-apoptotic Bcl-2 expression as indicated by Bax/Bcl-2 ratio when compared to untreated irradiated rats (Fig 10B), denoting suppression of apoptosis as a crucial event in the radiomitigative potential of EPO.

Fig 10. 


\section{Discussion}

Although the search for suitable, safe and effective radiation countermeasures was initiated more than half a century ago, it still represents a global challenge (Hofer et al. 2017). Remedies for the accidental exposure of individuals, as well as mass populations, to high doses of ionizing radiation are scarce (Gaberman et al. 2013). Radioprotectors are compounds that protect against radiation injury when given prior to radiation exposure. Whereas, radiomitigators can protect against radiation injury when given after exposure but before symptoms appear. Radioprotectors and radiomitigators can potentially improve the outcomes of radiotherapy for cancer therapy by allowing higher doses of radiation and/or reduced damage to normal tissues (Rosen et al. 2015). Preliminary studies of radioprotectors and mitigators typically involve investigation of the acute effects of TBI in rodents, using survival as the end-point. While TBI affects multiple organ systems, death in humans and rodents in the first 30 days is mainly due to two mechanisms: (1) gastrointestinal (GI) syndrome, which often leads to death within 10-12 days after exposure to 8-20Gy of $\gamma$-rays, due to fluid and electrolyte imbalance and bacterial translocation (sepsis); and (2) hematopoietic syndrome, which leads to death within 30 days after exposure to 3-8Gy, due to neutropenia and thrombocytopenia (Williams et al. 2010; Rosen et al. 2015; Booth et al. 2015). The devastating effects of radiation takes place within the first 30 days postexposure are termed as ARS or "radiation sickness", ARS shares similar patterns in humans and rodents, except that the LD50/30 values (dose of whole body exposure required to reduce survival to $50 \%$ by day 30 , without medical support) are lower in humans (ca. 3.5-4Gy) than in rodents (ca. 79Gy) (Hosseinimehr 2007).

The current investigation highlights, for the first time, the radiomitigative action of EPO against ARS using TBI rodent model. EPO is a well known glycoprotein cytokine and hematopoietic growth factor, which plays a pivotal role during later stages of erythroid maturation as well as proliferation, differentiation and survival of primitive hematopoietic stem and progenitor cells (Singh et al. 2014). Herein, we attempted to explore the potential effect of EPO on 30 days survival, BM and spleen cellularity, BM reconstitution and peripheral hematopoietic profile in sublethally irradiated rats. In addition, our study provides insight into the probable molecular mechanisms behind the radiomitigative effect of EPO in TBI model. In this study, a better understanding of the molecular targets might be involved in MOD that complicates ARS gives rise to novel strategies to counteract ARS and improves outcomes. 
In the present investigation, R- group exhibited typical signs of radiation sickness with median survival rate of day 20 and $70 \%$ mortality at day 30 of the survival analysis following TBI (Fig 1 A\&B). These results are in agreement with previous reports (Kaushik et al. 2012; Deng et al. 2015; Wang et al. 2015; Sato et al. 2015). Ionizing radiation can cause injury to GI and hematopoietic systems leading to defective hematopoiesis according to radiation dose, dose rate and radiation quality (Gridley et al. 2001; Ghosh et al. 2012; Soliman et al. 2015). This is followed by thrombocytopenia and concomitant hemorrhages beside effects in adaptive immune system resulting from deficient lymphopoiesis and apoptosis of lymphocytes (Wilkins et al. 2002). Sepsis is the primary cause of mortality during the early phase of the radiation-induced hematopoietic syndrome. Low levels of circulating immune blood cells and increased translocation of bacteria from the gastrointestinal tract into circulation and other tissues can lead to opportunistic infections and sepsis (Mauch et al. 1995; Ghosh et al. 2012). In R group, a significant reduction in body weight gain starting from the $1^{\text {st }}$ week post irradiation and continues till the $4^{\text {th }}$ week of the experimental course as compared to control and EPO + R groups as shown in Fig 2A\&B. These changes of body weight gain were coupled with a significant increase in liver mass index and marked decline in splenic index when compared to control and EPO $+\mathrm{R}$ groups (Fig 2B\&C). Similar reductions in body mass caused by irradiation have been well-documented (Moccia et al. 2010; El Shawi et al. 2015; Hasan et al. 2017). Weight reduction observed after irradiation of animals denotes severe toxicity, which might occur through biphasic changes. In the first phase, weight loss might due to gastrointestinal damage following irradiation, whereas the second phase of weight loss is associated with decreased water intake and increased rates of catabolic processes (Nakamura et al. 1968). Moreover, the increase in the liver mass index (\%) of R group when compared to control and EPO $+\mathrm{R}$ groups is suggestive of progressive hepatic damage and liver swelling in the irradiated rats. Our results are in agreement with previous studies (Pradeep et al. 2008; El Shawi et al. 2015). Consistently with previous findings (Jothy et al. 2016; Venkateswaran et al. 2016), we observed splenic atrophy after 30 days post irradiation with sublethal dose as revealed in Fig 2D. This might be due to multiple unrecoverable injuries and splenic depopulation induced by radiation (Bala and Kaur 2015), which in turn, leads to spleenocytes apoptosis and cell cycle arrest (Ha et al. 2013).

Results of the present study, clearly demonstrated the ability of EPO to mitigate acute radiation lethality as revealed by prolonged survival of $\mathrm{EPO}+\mathrm{R}$ group compared to $\mathrm{R}$ group (Fig $1 \mathrm{~A} \& \mathrm{~B}$ ). Also, EPO post-exposure treatment $24 \mathrm{hrs}$ following TBI recovered the body weight gain along the experimental time course (Fig 2A\&B), restored organ indices of liver and spleen with the remarkable 
absence of splenic atrophy (Fig 2 C\&D) and accelerated BM and spleen reconstitution and cellularity (Fig 3). Moreover, the ability of EPO post-exposure treatment to expedite recovery of the hematopoietic system seen here suggests that it is able to stimulate the proliferation and differentiation of spared stem cells in a regulated manner thereby; repopulating the blood compartments and the BM through hematopoiesis, mitigating TBI- induced lethality in rats (Fig 4\& 5). In this study, we observed a significant decrease in all hematological parameters and leukocytes differential in the blood at days 3 , 7, 15 and 30 after TBI in R group compared to control, suggesting the impaired hematopoiesis and myelosuppression. Proliferation of stromal cells and bone-marrow stromal layer formation are sensitive to radiation in vitro, while established bone-marrow stromal layer is relatively resistant to radiation (Zhang et al. 2010). Since the BM is a primary target for irradiation, the recovery was dependent on extramedullary cell division in the thymus and spleen (Abu-Sinna et al. 2005). TBI causes considerable decrease in the hematological values like erythrocytes, leukocytes and lymphocytes (Ashry et al. 2009; Soliman et al. 2015). Decrease in the number of erythrocytes in the present study was imputed to depletion of erythroblast differentiation and reticulocyte release from the BM and the loss of cells from the circulation by hemorrhage (Nunia et al. 2007). Moreover, depletion of lymphocytes in $\mathrm{R}$ group is attributed to radiation induced apoptosis and necrotic cell death (Zarybnicka et al. 2013). Leukocytes and lymphoid organs are also highly sensitive to radiation and oxidative stress (Soliman et al. 2015). Radiation does not only affect cell growth, proliferation, and viability as well as migration capacity of stem cells but also acts as a promoter of apoptosis (Ma et al. 2010). In individuals exposed to high doses of radiation, both mature lymphocytes and BM stem cells were severely damaged, causing profound depletion of granulocytes and natural killer cells, which together defend against microbial invasion, causing death from active infections (Wilkins et al. 2002). These previous investigations may explain the significant decline in both BM and spleen cellularity (Fig 3).

Expectedly, EPO post-exposure treatment exhibited a significant acceleration in RBCs and WBCs count restoration coupled with major recovery in $\mathrm{Hb}$ and PLT content as well as leukocytes differential as compared to R group (Fig 4\&5). This could be interpreted in the view that EPO enhance survival of erythroid progenitors cells through reducing their apoptosis via interaction with its receptor (EPO-R) expressed on them (Chateauvieux et al. 2011). EPO acts primarily on colony forming unit erythroid (CFU-E) inducing the proliferation and maturation through the stages of proerythroblast followed by reticulocytes and finally mature erythrocytes (Hillman and Henderson 1969; Singh et al. 2014). However, it acts synergistically with other growth factors to regulate the maturation and proliferation 
of erythroid cell development (Douay et al. 2009). This synergism stimulates pluripotent stem cell to differentiate into the CFU granulocyte, erythroid, monocyte, megakaryocyte (GEMM), and the myeloid stem cell. The CFU-GEMM then differentiates into the specific CFU for erythroid, granulocytes, monocytes, macrophages, eosinophils, and megakaryocytes cell precursors (Smith 1990). Under sublethal radiation stress, which is characterized by specific injury to the extravascular erythron, initial expansion and maturation of EPO-responsive erythroid progenitors exclusively in the BM, and subsequent reseeding of extramedullary sites, as spleen (Peslak et al. 2012). Coinciding with this notion, Kato et al. (1999) reported that EPO stimulates migration of BFU-E and CFU-E from BM to spleen. These effects might account for restored BM and spleen cellularity upon EPO treatment in irradiated rats.

Beside hematopoietic syndrome as a landmark event in ARS, exposure to high-dose radiation induces long-term damage in visceral organs such as highly radiosensitive liver and spleen. These delayed radiation effects may even lead to MOD syndrome (MODS) and life threatening multiple organ failure (MOF) (Williams and McBride 2011). Radiation-induced MODS/MOF (RI-MODS/ MOF) observed in irradiated patients appears to share similarities with the MODS/MOF occurring in shock, sepsis, pancreatitis or thermal burns, with progressive and sequential loss of function of vital organs (Mizock 2009). Irradiation-induced late organ damage has long been considered as resulting mainly from the loss of stem cells, leading to altered repopulation or abnormal tissue remodelling (Boittin et al. 2015). Moreover, MODS/MOF are considered as a consequence of uncontrolled acute and chronic inflammatory responses coupled with the damage to the vascular system contributes to the acute effects of TBI, and constitutes an important aspect of radiation injury (Williams and McBride 2011; Venkateswaran et al. 2016). Therefore, after irradiation, information regarding peripheral inflammation may be partly conveyed to brain nuclei through the vagus nerve, resulting in stimulation of antiinflammatory pathways that may include the hypothalamic-pituitary-adrenal (HPA) axis with subsequent anti-inflammatory hormone release, the cholinergic anti-inflammatory pathway (through efferent fibers of the vagus nerve) and also the sympathetic nervous system, which innervates peripheral and lymphoid organs (Fernandez et al. 2014). In addition, Chen et al. (2014) have elucidated the radioprotective effect of $\alpha-7-n A C h R$ activation on animal survival and intestinal injury. Several previous studies have demonstrated the pivotal role of JAK-2/STAT-3 pathway in the antiinflammatory and anti-apoptotic potential of $\alpha-7-n A C h R$ activation (de Jonge et al. 2005; Marrero and Bencherif 2009). Recently, Krafft et al. (2017) attributed the ameliorative effect of $\alpha-7-n A C h R$ stimulation on neuroinflammation to the JAK-2/STAT-3 signaling activation. In addition, wide array of 
cytoprotective, anti-inflammatory and anti-apoptotic activities elicited by EPO were mediated through JAK-2/STAT-3 activation (Zhao et al. 2011; Zhou and Yu 2013). In the same context, EPO treatment attenuated acute lung injury and MOD associated with systemic inflammatory conditions (Rocha et al. 2015) and improved outcome as well as survival in post- cardiac arrest syndrome (Xanthos et al. 2011). Hence, we focused our study on the implication of $\alpha-7-n A C h R-J A K-2 / S T A T-3$ axis and subsequent redox sensitive Nrf-2/HO-1 signaling in ARS and MODS in irradiated rats and possible radiomitigative effect of EPO.

Strikingly, our findings revealed a profound downregulation in hepatic and splenic protein expression of JAK-2, p-JAK-2, STAT-3, p-STAT-3 with increased JAK-2/STAT-3 to p-JAK-2/p-STAT-3 ratio as well as a significant reduction in hepatic and splenic $\alpha-7-n A C h R$ protein expression (Fig 7A-G), concomitantly with significant suppression in Nrf-2 gene expression and its molecular targets HO-1 (Fig 8), NQO-1 and TRXR gene expression (Fig 9A) 30 days after TBI in R group as compared to the control set. Ionizing radiation inflicted cellular injuries are primarily attributed to deleterious effect of free radicals and ROS generation (Srivastava et al. 2014). Irradiation induced ROS generation is a result of imbalance between production of free radicals and antioxidant defense mechanisms and is characterized by an increase in ROS and MDA as well as decrease in the antioxidant machinery (Zhu et al. 2007). Indeed, our findings implied a significant rise in oxidative stress markers (MDA and NO) levels in liver and spleen 30 days post irradiation in R group compared to control group (Fig 9B\& C).This is in line with findings were obtained by Marina et al. (2015) and Zhou et al. (2017). Nrf2 is a transcription factor and a cellular sensor of oxidative stress (Pan et al. 2016). Moreover, Nrf2 is found to promote the survival of irradiated cells, including BM cells, through ROS scavenging (Sekhar and Freeman 2015). Nrf-2 has a short half life (Itoh et al. 2003). Therefore, it is upregulated in early stage of radiation induced oxidative stress, 7 days post exposure and showed a reduced expression in late stages, after 30 days (Marina et al. 2015). In agreement with our data, this might be explained that radiation induced excessive oxidative stress and ROS generation, which in turn, lead to upregulated Nrf-2 gene expression at early stage response (hours to few days) that was followed by significant downregulation of Nrf-2 and its molecular targets (HO-1, NQO-1 and TRXR) at later stages thanks to the exhaustion and depletion of this system. In the same context, the pro-survival JAK-2/STAT-3 signaling is assumed to be upregulated post irradiation (Gao et al. 2014). In contrast, our data indicated impaired JAK-2/STAT-3 signaling, which is correlated with overexpression of suppressor of cytokine signaling 3 (SOCS3) (Linard et al. 2004). Moreover, the major factor contributes to deficit in $\alpha$-7nAChR expression is oxidative stress (Gao et al. 2008). 
Interestingly, EPO post exposure treatment of irradiated rats $(\mathrm{EPO}+\mathrm{R})$ markedly upregulated JAK-2, p-JAK-2, STAT-3, p-STAT-3 with increased p-JAK-2/p-STAT-3 to JAK-2/STAT-3 ratio, suggesting activation of JAK-2/STAT-3 signaling and boosted expression of the cholinergic anti-inflammatory $\alpha$ 7-nAChR in liver and spleen compared to R group (Fig 7A-G). Furthermore, EPO post exposure treatment restored redox balance via reducing oxidative stress markers (MDA and NO) and enhancing expression of redox regulator genes (Nrf-2, HO-1, NQO-1 and TRXR-1) in hepatic and splenic tissues versus $\mathrm{R}$ group. In non-eryhtroid tissues, EPO acts principally through JAK-2/STAT-3 activation (Alnaeeli et al. 2014). A plausible mechanism by which EPO modulates $\alpha-7-n A C h R$ expression is through upregulation of unphosphorylated STAT-3 expression (Peña et al. 2010). Therefore, EPO might act as positive allosteric modulator for $\alpha-7-n A C h R$. Moreover, EPO promoted expression of Nrf2 and its downstream targets (HO-1, NQO-1 and TRXR-1), which played both antioxidant and antiinflammatory roles in liver and spleen of TBI rats. This antioxidant potential of EPO has been well documented (Osikov et al. 2015). Worthwhile, EPO post exposure treatment recovered arginase activity that was inhibited by radiation (Fig 9D). Induction of iNOS expression and a marked generation of NO characterize an early-phase of radiation response, and increased generation of ornithine and its metabolism to polyamines are important elements of the repair-phase response to the injury (Shukla et al. 2009). Arginase-mediated conversion of arginine to ornithine is the initial step in polyamine synthesis and plays an important role in cellular proliferation (Tong and Barbul 2004). Since polyamines are involved in the tissue regeneration, this shift in the L-arginine pathway toward ornithine production is very favorable for the host recovery from radiation injury. Arginase function is central to regulating overall arginine availability and cross-regulating the expression of iNOS production (Shukla et al. 2009). This could be reflected on decreased NO level in liver and spleen (Fig 9C) concurrently with increased serum level of anti-inflammatory cytokine IL-10 (Fig 9E), which is produced in large amount from activated B-lymphocytes in spleen (Gotoh et al. 2012). IL-10 has been shown to slow down progression of apoptosis in immune-derived cells and decreased serum level implies splenic hypo-function and atrophy (Hassan et al. 2014). Accordingly, EPO treatment in irradiated rats significantly reduced expression of the pro-apoptotic genes (Bax and p53) and upregulated expression of anti-apoptotic genes (Bcl-2) as well as obviously diminished Bax/Bcl-2 ratio in hepatic and splenic tissues paralleled by diminished caspase-3 activity in both tissues (Fig 10); however, no significant change was recorded in hepatic p53 mRNA expression, since liver and spleen show variable degree of radiosensitivity (Komarova et al. 2000). Thus, EPO treatment prevented apoptosis and favored survival of hepatic and splenic tissues against insults induced by radiation. 


\section{Conclusion}

Eventually, the current study clearly demonstrated that EPO when administered 24 hours post TBI efficiently mitigated sublethal radiation associated lethality and prolonged survival of irradiated animals, alleviated radiation- induced hematopoietic injury, myelotoxicity and BM suppression, which is contributed by multiple factors such as (i) augmentation of the hematopoietic progenitors in BM and spleen, (ii) restoration of BM and spleen cellularity, (iii) afforded liver and spleen protection through decreasing ROS and boosting antioxidant capacity as well as prevented apoptosis. In addition, activation of the cholinergic anti-inflammatory pathway ( $\alpha-7-n A C h R)$ and pro-survival JAK-2/STAT-3 signaling and subsequent stimulation of Nrf-2 antioxidant machinery contributes to the mitigative potential against MODS/MOF in ARS. These observations unequivocally render EPO as an attractive countermeasure against acute radiation insults.

\section{Acknowledgment}

The authors are grateful to Prof. Adel Kholoussy, Department of Pathology, Faculty of Veterinary Medicine, Cairo University, Cairo, Egypt, for accomplishing the histopathological examination of the liver and spleen sections in this study.

\section{Author contribution}

All of the authors participated equally in this work.

\section{References}

Abu-Sinna, G., Kafafy, Y.A., Nassar, A.Y. and Salman, M.A. 2005. Synergistic effect of bone marrow transplantation and bradykinin potentiating factor isolated from venom on thymus and spleen of sublethally irradiated guinea pig. The Egyptian Journal of Radiation Science. 18(2): 249-255.

Al-Attar, A.M. and Zari, T.A. 2010. Influences of crude extract of tea leaves, Camellia sinensis, on streptozotocin diabetic male albino mice. Saudi J. Biol. Sci. 17(4): 295-301. doi:10.1016/j.sjbs.2010.05.007. PMID: 23961092.

Alnaeeli, M., Raaka, B.M., Gavrilova, O., Teng, R., Chanturiya, T. and Noguchi, C.T. 2014. Erythropoietin signaling: A novel regulator of white adipose tissue inflammation during diet-induced obesity. Diabetes. 63(7): 2415- 31. doi: 10.2337/db13-0883. 
Arcasoy, M.O. 2010. Non-erythroid effects of erythropoietin. Haematologica. 95(11): 1803-5.

Ashry, O.M., Hussein, E.M. and Salama, S.F. 2009. Boosting of antioxidant defense by interferonalpha in irradiated bone marrow transplantation rats. The Egyptian Journal of Radiation Science. 22(1): $19-33$.

Bala, M. and Kaur, P. 2015. Changes in spleen cell populations in total body ${ }^{60} \mathrm{CO}$-gamma irradiated mice and their modification by SBL-1: Implication in radiation protection. Int. J. Pharm. Sci. Rev. Res. 34(1): 109-113.

Banchroft, J.D., Stevens, A. and Turner, D.R. 1996. Theory and practice of histological techniques. $4^{\text {th }}$ ed. Churchill, Livingstone.

Barry, S.P., Townsend, P.A., Latchman, D.S. and Stephanou, A. 2007. Role of the JAK-STAT pathway in myocardial injury. Trends in Molecular Medicine 13(2): 82-89.

Becerra-Díaz, M., Valderrama-Carvajal, H. and Terrazas, L.I. 2011. Signal Transducers and Activators of Transcription (STAT) family members in helminth infections. Int. J. Biol. Sci. 7(9): 1371-81.

Boittin, F.X., Denis, J., Mayol, J.F., Martigne, P., Raffin, F., Coulon, D., et al. 2015. The extent of irradiation-induced long-term visceral organ damage depends on cranial/brain exposure. PloS One. 10(4): e0122900. doi: 10.1371/journal.pone.0122900.

Booth, C., Tudor, G.L., Katz, B.P. and MacVittie, T.J. 2015. The Delayed Effects of Acute Radiation Syndrome: Evidence of Long-Term Functional Changes in the Clonogenic Cells of the Small Intestine. Health Phys. 109(5): 399-413. doi: 10.1097/HP.0000000000000356.

Chateauvieux, S., Grigorakaki, C., Morceau, F., Dicato, M. and Diederich, M. 2011. Erythropoietin, erythropoiesis and beyond. Biochem. Pharmacol. 82(10): 1291-303. doi: 10.1016/j.bcp.2011.06.045.

Chen, E., Staudt, L.M. and Green, A.R. 2012. Janus kinase deregulation in leukemia and lymphoma. Immunity 36(4): 529-41. doi: 10.1016/j.immuni.2012.03.017. 
Chen, J.K., Li, Z.P., Liu, Y.Z., Zhao, T., Zhao, X.B., Ni, M., et al. 2014. Activation of alpha 7 nicotinic acetylcholine receptor protects mice from radiation-induced intestinal injury and mortality. Radiat. Res. 181(6): 666-71. doi: 10.1667/RR13575.1.

Dacie, J.V. and Lewis, S.M. 2001. Practical haematology, $7^{\text {th }}$ ed., Edinburgh, Churchill Livingstone. David, R.B., Sjaastad, Ǿ.V., Blom, A.K., Skogtvedt, S. and Harbitz, I. 2005. Ontogeny of erythropoietin receptor mRNA expression in various tissues of the foetal and the neonatal pig. Domestic Animal Endocrinol. 29(3): 556- 563. https://doi.org/10.1016/j.domaniend.2005.02.013. de Jonge, W.J., van der Zanden, E.P., The, F.O., Bijlsma, M.F., van Westerloo, D.J., Bennink, R.J., et al. 2005. Stimulation of the vagus nerve attenuates macrophage activation by activating the Jak2STAT3 signaling pathway. Nat. Immunol. 6(8): 844-51.

Deng, W., Kimura, Y., Gududuru, V., Wu, W., Balogh, A., Szabo, E., et al. 2015. Mitigation of the hematopoietic and gastrointestinal acute radiation syndrome by octadecenyl thiophosphate, a small molecule mimic of lysophosphatidic acid. Radiat. Res. 183(4): 465-75. doi: 10.1667/RR13830.1.

Dinkova-Kostova, A.T. and Abramov, A.Y. 2015. The emerging role of Nrf2 in mitochondrial function. Free Radic. Biol. Med. 88(Pt B): 179-188.

Douay, L., Lapillonne, H. and Turhan, A.G. 2009. Stem cells--a source of adult red blood cells for transfusion purposes: present and future. Crit. Care Clin. 25(2): 383-98. doi: 10.1016/j.ccc.2008.12.008.

El Shawi, O.E., Abd El-Rahman, S.S. and Abd El Hameed, M. 2015. Reishi mushroom attenuates hepatic inflammation and fibrosis induced by irradiation enhanced carbon tetrachloride in rat model. J. Biosci. Med. 3: 24-38. doi:10.4236/jbm.2015.310004.

Elshiekh, M., Kadkhodaee, M., Seifi, B., Ranjbaran, M. and Ahghari, P. 2015. Ameliorative effect of recombinant human erythropoietin and ischemic preconditioning on renal ischemia reperfusion injury in rats. Nephro. Urol. Mon. 7(6): e31152. doi: 10.5812/numonthly.31152. 
Fernandez, R., Nardocci, G., Navarro, C., Reyes, E.P., Acuña-Castillo, C. and Cortes, P.P. 2014. Neural reflex regulation of systemic inflammation: potential new targets for sepsis therapy. Front. Physiol. 5: 489. doi: 10.3389/fphys.2014.00489.

Gaberman, E., Pinzur, L., Levdansky, L., Tsirlin, M., Netzer, N., Aberman, Z., et al. 2013. Mitigation of Lethal Radiation Syndrome in Mice by Intramuscular injection of 3D cultured adherent human placental stromal cells. PloS One. 8(6): e66549. doi: 10.1371/journal.pone.0066549.

Gammella, E., Diaz, V., Recalcati, S., Buratti, P., Samaja, M., Dey, S., et al. 2015. Erythropoietin's inhibiting impact on hepcidin expression occurs indirectly. Am. J. Physiol. Regul. Integr. Comp. Physiol. 308(4): R330-5. doi: 10.1152/ajpregu.00410.2014.

Gao, L., Li, F.S., Chen, X.H., Liu, Q.W., Feng, J.B., Liu, Q.J., et al. 2014. Radiation induces phosphorylation of STAT3 in a dose- and time-dependent manner. Asian Pac. J. Cancer Prev. 15(15): $6161-4$

Gao, Q., Liu, Y.J. and Guan, Z.Z. 2008. Oxidative stress might be a mechanism connected with the decreased $\alpha 7$ nicotinic receptor influenced by high-concentration of fluoride in SH-SY5Y neuroblastoma cells. Toxicology in Vitro. 22(4): 837- 43. https://doi.org/10.1016/j.tiv.2007.12.017.

Genc, S., Koroglu, T.F. and Genc, K. 2004. Erythropoietin and the nervous system. Brain Res. 1000(12): 19-31.

Ghosh, S.P., Kulkarni, S., Perkins, M.W., Hieber, K., Pessu, R.L., Gambles, K., et al. 2012. Amelioration of radiation-induced hematopoietic and gastrointestinal damage by Ex-RAD(R) in mice. J. Radiat. Res. 53(4): 526-36.

Gotoh, K., Inoue, M., Masaki, T., Chiba, S., Shimasaki, T., Ando, H., et al. 2012. A novel antiinflammatory role for spleen-derived interleukin-10 in obesity-induced hypothalamic inflammation. J. Neurochem. 120(5): 752-64. doi: 10.1111/j.1471-4159.2011.07617.x. 
Gridley, D.S., Pecaut, M.J., Miller, G.M., Moyers, M.F. and Nelson, G.A. 2001. Dose and dose rate effects of whole-body gamma-irradiation: II. Haematological variables and cytokines. In Vivo. 15(3): $209-216$.

Ha, C.T., Li, X.H., Fu, D., Xiao, M. and Landauer, M.R. 2013. Genistein nanoparticles protect mouse hematopoietic system and prevent proinflammatory factors after gamma irradiation. Radiat Res. 180(3): 316-25. doi: 10.1667/RR3326.1.

Hasan, H.F., Abdel-Rafei, M.K. and Galal, S.M. 2017. Diosmin attenuates radiation-induced hepatic fibrosis by boosting PPAR- $\gamma$ expression and hampering miR-17-5p-activated canonical Wnt- $\beta$-catenin signaling. Biochem. Cell. Biol. 95(3): 400-414. doi: 10.1139/bcb-2016-0142.

Hassan, Z.A., Arafa, M.H., Soliman, W.I., Atteia, H.H. and Al-Saeed, H.F. 2014. The effects of monosodium glutamate on thymic and splenic immune functions and role of recovery (biochemical and histological study). J. Cytol. Histol. 5: 1-9. doi:10.4172/2157-7099.1000283.

Hillman, R.S. and Henderson, P.A. 1969. Control of marrow production by the level of iron supply. J. Clin. Invest. 48(3): 454-60.

Hofer, M., Hoferová, Z., Depeš, D. and Falk, M. 2017. Combining pharmacological countermeasures to attenuate the acute radiation syndrome- A concise review. Molecules 22(5): pii: E834. doi: 10.3390/molecules22050834.

Hossain, M. and Uma Devi, P. 2000. Effect of irradiation at the early fetal stage on adult brain function in the mouse: locomotor activity. Int. J. Radiat. Biol. 76(10): 1397-402.

Hosseinimehr, S.J. 2007. Trends in the development of radioprotective agents. Drug Discov. Today. 12(19-20): 794-805.

Itoh, K., Wakabayashi, N., Katoh, Y., Ishii, T., O'Connor, T. and Yamamoto, M. 2003. Keap1 regulates both cytoplasmic-nuclear shuttling and degradation of Nrf2 in response to electrophiles. Genes Cells. 8(4): 379-91. 
Jackson, W.L., Jr., Gallagher, C., Myhand, R.C. and Waselenko, J.K. 2005. Medical management of patients with multiple organ dysfunction arising from acute radiation syndrome. BJR Suppl. 27: 161168.

Jaeschke, H. and McGill, M.R. 2013. Serum Glutamate Dehydrogenase-Biomarker for Liver Cell Death or Mitochondrial Dysfunction? Toxicol. Sci. 134(1): 221-2. doi: 10.1093/toxsci/kft087.

Jothy, S.L., Saito, T., Kanwar, J.R., Chen, Y., Aziz, A., Yin-Hui, L., et al. 2016. Radioprotective activity of Polyalthia longifolia standardized extract against X-ray radiation injury in mice. Phys. Med. 32(1): 150-61. doi: 10.1016/j.ejmp.2015.10.090.

Kato, M., Kato, Y. and Sugiyama, Y. 1999. Mechanism of the upregulation of erythropoietin-induced uptake clearance by the spleen. Am. J. Physiol. 276(5 Pt 1): E887-95.

Kaushik, P., Mathur, M., Rawat, N. and Dutt, P. 2012. Radioprotective effect of alcoholic extract of Mentha piperita (linn) on swiss albino mice exposed to whole body gamma irradiation: A preliminary study. Int. J. Pharm. Bio. Sci. 3: 598- 610.

Komarova, E.A., Christov, K., Faerman, A.I. and Gudkov, A.V. 2000. Different impact of p53 and p21 on the radiation response of mouse tissues. Oncogene. 19(33): 3791-3798 http://dx.doi.org/10.1038/sj.onc.1203717.

Krafft, P.R., McBride, D., Rolland, W.B., Lekic, T., Flores, J.J. and Zhang, J.H. 2017. $\alpha-7$ Nicotinic acetylcholine receptor stimulation attenuates neuroinflammation through jak2-stat3 activation in murine models of intracerebral hemorrhage. BioMed Research International. 1-13. https://doi.org/10.1155/2017/8134653.

Lefevre, G., Beljean-Leymarie, M., Beyerle, F., Bonnefont-Rousselot, D., Cristol, J.P., Thérond, P., et al. 1998. Evaluation of lipid peroxidation by measuring thiobarbituric acid reactive substances. Ann. Biol. Clin. (Paris) 56(3): 305-319. 
Linard, C., Marquette, C., Mathieu, J., Pennequin, A., Clarençon, D. and Mathé, D. 2004. Acute induction of inflammatory cytokine expression after $\gamma$-irradiation in the rat: effect of an NF- $\kappa \mathrm{B}$ inhibitor. Int. J. Radiat. Oncol. Biol. Physics. 58(2): 427-434.

Livak, K.J. and Schmittgen, T.D. 2001. Analysis of relative gene expression data using real-time quantitative PCR and the 2(-Delta Delta C (T)) method. Methods 25(4): 402-408. doi:10.1006/meth.2001.1262. PMID: 11846609.

Loboda, A., Damulewicz, M., Pyza, E., Jozkowicz, A. and Dulak, J. 2016. Role of Nrf2/HO-1 system in development, oxidative stress response and diseases: an evolutionarily conserved mechanism. Cell. Mol. Life Sci. 73(17): 3221-47. doi: 10.1007/s00018-016-2223-0.

Ma, X.H., Guo, W., Liu, X.P., Yin, T., Jia, X., Xiong, J., et al. 2010. Effect of ${ }^{60}$ Co $\gamma$ - radiation on mesenchymal stem cells (MSCs) proliferation and differentiation. African Journal of Microbiology Research. 4(20): 2161-2168.

Marina, R., González, P., Ferreras, M.C., Costilla, S. and Barrio, J.P. 2015. Hepatic Nrf2 expression is altered by quercetin supplementation in X-irradiated rats. Mol. Med. Rep. 11(1): 539-46. doi: 10.3892/mmr.2014.2741.

Marrero, M.B. and Bencherif, M. 2009. Convergence of alpha 7 nicotinic acetylcholine receptoractivated pathways for anti-apoptosis and anti-inflammation: central role for JAK2 activation of STAT3 and NF-kappaB. Brain Res. 1256: 1-7. doi: 10.1016/j.brainres.2008.

Mauch, P., Constine, L., Greenberger, J., Knospe, W., Sullivan, J., Liesveld, J.L., et al. 1995. Hematopoietic stem cell compartment: acute and late effects of radiation therapy and chemotherapy. Int. J. Radiat. Oncol. Biol. Phys. 31(5): 1319-39.

Mingone, C.J., Gupte, S.A., Quan, S., Abraham, N.G. and Wolin, M.S. 2003. Influence of heme and heme oxygense-1 transfection of pulmonary microvascular endothelium on oxidant generation and cGMP. Exp. Biol. Med. (Maywood). 228(5): 535-539. PMID: 12709582. 
Miranda, K.M., Espey, M.G. and Wink, D.A. 2001. A rapid, simple spectrophotometric method for simultaneous detection of nitrate and nitrite. Nitric Oxide 5(1): 62-71. doi:10.1006/niox.2000.0319. PMID: 11178938.

Mizock, B.A. 2009. The multiple organ dysfunction syndrome. Dis. Mon. 55: 476-526. doi: 10.1016/j.disamonth.2009.04.002.

Moccia, K.D., Olsen, C.H., Mitchell, J.M. and Landauer, M.R. 2010. Evaluation of hydration and nutritional gels as supportive care after total-body irradiation in mice (Mus musculus). J. Am. Assoc. Lab. Anim. Sci. 49(3): 323-328. PMID: 20587164.

Nakamura, W., Kojima, E., Minamizawa, H., Kankura, T., Kabayashi, S. and Eto, H. 1968. In Comparative cellular and species radiosensitivity in animals. In: Bond, V.P. and Sugahara, T. IgakuShoin, Tokyo, Japan.

Nunia, V., Sncheti, G. and Goyal, P.K. 2007. Protection of Swiss albino mice against whole-body gamma irradiation by diltiazem. Br. J. Radiol. 80(950): 77-84. http://dx.doi.org/10.1259/bjr/41714035.

Omar, H.A., Sargeant, A.M., Weng, J.R., Wang, D., Kulp, S.K., Patel, T., et al. 2009. Targeting of the Akt-nuclear factor-kappa B signaling network by [1-(4-chloro-3-nitrobenzenesulfonyl)-1H-indol-3-yl]methanol (OSU-A9), a novel indole-3-carbinol derivative, in a mouse model of hepatocellular carcinoma. Mol. Pharmacol. 76(5): 957-968. doi:10.1124/mol.109.058180. PMID: 19706731.

Osikov, M.V., Telesheva, L.F., Ageev, Y.I. 2015. Antioxidant Effect of Erythropoietin during Experimental Chronic Renal Failure. Bull. Exp. Biol. Med. 160(2): 202-4. doi: 10.1007/s10517-0153128-X.

Özyurt, H., Özden, A.S., Çevik, Ö., Özgen, Z., Cadirci, S., Elmas, M.A., et al. 2014. Investigation into the role of the cholinergic system in radiation-induced damage in the rat liver and ileum. J. Radiat. Res. 55(5): $866-75$. 
Pan, H., Guan, D., Liu, X., Li, J., Wang, L., Wu, J., et al. 2016. SIRT6 safeguards human mesenchymal stem cells from oxidative stress by coactivating NRF2. Cell Res. 26(2): 190-205. doi: 10.1038/cr.2016.4.

Pappano, A.J. 2007. Cholinoceptor activating and cholinesterase inhibiting drugs, cholinoceptor blocking drugs, in: B.G. Katzung (Eds.), Basic and Clinical Pharmacology, 10th edn. Boston: McGraw Hill, 2007, pp. 93-120.

Peña, G., Cai, B., Liu, J., van der Zanden, E.P., de Jonge, D.W.J. and Ulloa, L. 2010. Unphosphorylated STAT3 modulates alpha7 nicotinic receptor signaling and cytokine production in sepsis. Eur. J. Immunol. 40(9): 2580-2589. doi: 10.1002/eji.201040540.

Peslak, S.A., Wenger, J., Bemis, J.C., Kingsley, P.D., Koniski, A.D., McGrath, K.E., et al. 2012. EPOmediated expansion of late-stage erythroid progenitors in the bone marrow initiates recovery from sublethal radiation stress. Blood. 120(12): 2501-11. doi: 10.1182/blood-2011-11-394304.

Pradeep, K., Park, S.H. and Ko, K.C. 2008. Hesperidin a flavanoglycone protects against gamma irradiation induced hepatocellular damage and oxidative stress in Sprague-Dawley rats. Eur. J. Pharmacol. 587(1-3): 273-280. doi:10.1016/j.ejphar.2008.03.052. PMID: 18485345.

Reitman, S. and Frankel, S.A. 1957. A colourimetric method for the determination of serum oxaloaetic and glutamic pyruvic transaminases. Am. J. Clin. Pathol. 28(1): 56-63.

Rocha, J., Eduardo-Figueira M, Barateiro A, Fernandes A, Brites D, Pinto R, et al. 2015. Erythropoietin reduces acute lung injury and multiple organ failure/dysfunction associated to a scaldburn inflammatory injury in the rat. Inflammation 38(1): 312- 26.

Rosen, E.M., Day, R. and Singh, V.K. 2015. New approaches to radiation protection. Front. Oncol. 4: 381. doi: 10.3389/fonc.2014.00381.

Sato, T., Kinoshita, M., Yamamoto, T., Ito, M., Nishida, T., Takeuchi, M., et al. 2015. Treatment of irradiated mice with high-dose ascorbic acid reduced lethality. PloS One. 10(2): e0117020. doi: 10.1371/journal.pone.0117020. 
Sekhar, K.R. and Freeman, M.L. 2015. Nrf2 promotes survival following exposure to ionizing radiation. Free Radic. Biol. Med. 88(Pt B): 268-74. doi: 10.1016/j.freeradbiomed.2015.04.035.

Shukla, J., Chatterjee, S., Thakur, V.S., Premachandran, S., Checker, R. and Poduval, T.B. 2009. LArginine reverses radiation-induced immune dysfunction: the need for optimum treatment window. Radiat. Res. 171(2): 180-7. doi: 10.1667/RR1241.1.

Singh, V.K., Saini, A. and Chandra, R. 2014. Role of Erythropoietin and Other Growth Factors in Ex Vivo Erythropoiesis. Advances in Regenerative Medicine. http://dx.doi.org/10.1155/2014/426520 Smith, B.R. 1990. Regulation of hematopoiesis. Yale J. Biol. Med. 63(5): 371- 380.

Soliman, M.G., Ashry, O.M., Ahmed, M.A.E. and Abd El-Naby, Y.H. 2015. Improvement of hematopoietic and immunologic findings in sublethal gamma irradiated rats treated with bone marrow transplantation and wheat germ oil. J. of Immune Based Therapies, Vaccines and Antimicrobials 4(2): 9-18.doi: http://dx.doi.org/10.4236/jibtva.2015.42002.

Srivastava, N.N., Shukla, S.K., Yashavarddhan, M.H., Devi, M., Tripathi, R.P. and Gupta, M.L. 2014. Modification of radiation-induced DNA double strand break repair pathways by chemicals extracted from Podophyllum hexandrum: an in vitro study in human blood leukocytes. Environ. Mol. Mutagen. 55(5): 436-48. doi: 10.1002/em.21853.

Tong, B.C. and Barbul, A. 2004. Cellular and physiological effects of arginine. Mini Rev. Med. Chem. 4(8): $823-32$.

Venkateswaran, K., Shrivastava, A., Agrawala, P.K., Prasad, A., Kalra, N., Pandey, P.R., et al. 2016. Mitigation of radiation-induced hematopoietic injury by the polyphenolic acetate 7, 8-diacetoxy-4methylthiocoumarin in mice. Sci. Rep. 6: 37305. doi: 10.1038/srep37305.

Wang, Z., Yang, W.L., Jacob, A., Aziz, M. and Wang, P. 2015. Human ghrelin mitigates intestinal injury and mortality after whole body irradiation in rats. PLoS One. 10(2): e0118213. doi: 10.1371/journal.pone.0118213. 
Wei, X., Wei, H., Lin, W., Hu, Z. and Zhang, J. 2017. Cell death biomarker M65 is a useful indicator of liver inflammation and fibrosis in chronic hepatitis B: A cross-sectional study of diagnostic accuracy. Medicine (Baltimore) 96(20): e6807. doi: 10.1097/MD.0000000000006807.

Wilkins, R.C., Wilkinson, D., Maharaj, H.P., Bellier, P.V., Cybulski, M.B. and McLean, J.R.N. 2002. Differential apoptotic response to ionizing radiation in subpopulations of human white blood cells. Mutat. Res. 513(1-2): 27-36. http://dx.doi.org/10.1016/S1383-5718(01)00290-X.

Williams, J.P. and McBride, W.H. 2011. After the bomb drops: a new look at radiation-induced multiple organ dysfunction syndrome (MODS). Int. J. Radiat. Biol. 87(8): 851-68. doi: 10.3109/09553002.2011.560996.

Williams, J.P., Brown, S.L., Georges, G.E., Hauer-Jensen, M., Hill, R.P., Huser, A.K., et al. 2010. Animal models for medical countermeasures to radiation exposure. Radiat Res. 173(4): 557-78. doi: 10.1667/RR1880.1.

Witthuhn, B.A., Quelle, F.W., Silvennoinen, O., Yi, T., Tang, B., et al. 1993. JAK2 associates with the erythropoietin receptor and is tyrosine phosphorylated and activated following stimulation with erythropoietin. Cell 74(2): 227-36.

Xanthos, T., Vasileiou, P.V., Kakavas, S., Syggelou, A. and Iacovidou, N. 2011. The potential role of erythropoietin as a pleiotropic agent in post-cardiac arrest syndrome. Curr. Pharm. Des. 17(15): 151729.

Yeboah, M.M., Xue, X., Javdan, M., Susin, M. and Metz, C.N. 2008. Nicotinic acetylcholine receptor expression and regulation in the rat kidney after ischemia-reperfusion injury. Am. J. Physiol. Renal Physiol. 295(3): F654-61. doi: 10.1152/ajprenal.90255.2008.

Zarybnicka, L., Vavrova, J., Havelek, R., Tichy, A., Pejchal, J. and Sinkorova, Z. 2013. Lymphocyte subsets and their H2AX phosphorylation in response to in vivo irradiation in rats. Int. J. Rad. Biol. 89(2): 110-117. doi: 10.3109/09553002.2012.721050. 
Zhang, Z., Zhang, H., Liu, F., Qiu, M. and Tong, J. 2010. Effects of gamma radiation on bone-marrow stromal cells. J. Toxicol. Environ. Health A. 73(7): 514-9. doi: 10.1080/15287390903523477.

Zhao, J., Li, G., Zhang, Y., Su, X. and Hang, C. 2011. The potential role of JAK2/STAT3 pathway on the anti-apoptotic effect of recombinant human erythropoietin (rhEPO) after experimental traumatic brain injury of rats. Cytokine. 56(2): 343-50. doi: 10.1016/j.cyto.2011.07.018.

Zhou, K., Boström, M., Ek, C.J., Li, T., Xie, C., Xu, Y., et al. 2017. Radiation induces progenitor cell death, microglia activation, and blood-brain barrier damage in the juvenile rat cerebellum. Sci. Rep. 7: 46181. doi: 10.1038/srep46181.

Zhou, T.F. and Yu, J.G. 2013. Recombinant human erythropoietin attenuates neuronal apoptosis and cognitive defects via JAK2/STAT3 signaling in experimental endotoxemia. J Surg. Res. 183(1): 30412. doi: $10.1016 /$ j.jss.2012.11.035.

Zhu, C., Xu, F., Fukuda, A., Wang, X., Fukuda, H., Korhonen, L., et al. 2007. X chromosome-linked inhibitor of apoptosis protein reduces oxidative stress after cerebral irradiation or hypoxia-ischemia through up-regulation of mitochondrial antioxidants. Eur. J. Neurosci. 26(12): 3402-10.

Figure Legends:

Fig 1. Effect of EPO on the survival of rats irradiated with sub-lethal dose $(7 \mathrm{~Gy})$ of gamma radiation. Rats ( $\mathrm{n}=20$ rats/group) were exposed to a single sub-lethal dose (7 Gy) TBI and treated with vehicle or EPO (5000 IU/Kg; i.p.) 24 hours post-irradiation to TBI and were observed for 30 days. A) The survival rate was estimated by using Kaplan- meier method and compared by Mantel-Cox (Log Rank) and GehanBreslow- Wilcoxon statistics $(* * * \mathbf{P}<0.0001$; Chi- square $=41.63)$. B) Survival score summary of the surviving animals in different groups. Data are expressed as mean values \pm S.E.M. Statistical analysis was carried out using one way ANOVA followed by Tukey- Kramer multiple comparisons test, *P< 0.05 versus $(C)$, \# $P<0.05$ versus $(R)$, and $@ P<0.05$ versus $(\mathrm{EPO}+\mathrm{R})$.

Fig 2. EPO post- exposure treatment attenuates radiation- induced body weight changes. Animal body weights were monitored at the beginning of each week for 4 weeks. A) Changes in body weight throughout 30 days of experimental course. B) Percent change in body weight. C) Liver index and D) 
spleen index. Data are expressed as mean values \pm S.E.M. Statistical analysis was carried out using one way ANOVA followed by Tukey- Kramer multiple comparisons test, $* P<0.05$ versus $(C), \# P<0.05$ versus $(\mathrm{R})$, and @ $\mathrm{P}<\mathbf{0 . 0 5}$ versus $(\mathrm{EPO}+\mathrm{R})$.

Fig 3. Effect of EPO post- exposure treatment on BM and spleenocytes cellularity after TBI. Data are expressed as mean values \pm S.E.M. Statistical analysis was carried out using one way ANOVA followed by Tukey- Kramer multiple comparisons test, $* \mathrm{P}<0.05$ versus $(\mathrm{C}), \# \mathrm{P}<0.05$ versus $(\mathrm{R})$, and @ $\mathrm{P}<0.05$ versus (EPO+ R).

Fig 4. EPO mitigates TBI- induced pancytopenia in rats. Alterations in the hematological indices in the peripheral blood by EPO. Rats were subjected to TBI followed by administration of EPO at 24 hours and assessed for blood cell parameters. Blood counts showing A) RBCs, B) WBCs, C) Hb, D) HCT and E) PLT at days 3, 7, 15 and 30 post TBI. Data are expressed as mean values \pm S.E.M. Statistical analysis was carried out using one way ANOVA followed by Tukey- Kramer multiple comparisons test, $* \mathbf{P}<0.05$ versus (C), \# $P<0.05$ versus $(R)$, and $@ P<0.05$ versus $(E P O+R)$.

Fig 5. EPO post- exposure treatment ameliorates leukocyte differential of irradiated rats. Restoration of hematopoietic stem cells upon EPO administration to TBI rats. Estimation of A) Lymphocytes, B) Monocytes, C) Neutrophils and D) Eosinophils percentages at days 3, 7, 15 and 30 post TBI. Data are expressed as mean values \pm S.E.M. Statistical analysis was carried out using one way ANOVA followed by Tukey- Kramer multiple comparisons test, ${ }^{*} \mathrm{P}<0.05$ versus $(\mathrm{C}), \# \mathbf{P}<0.05$ versus $(\mathrm{R})$, and $@ \mathbf{P}<0.05$ versus (EPO+ R).

Fig 6. EPO post- exposure treatment alleviates hepatotoxicity biomarkers of irradiated rats. Serum biomarkers of hepatotoxicity A) AST and ALT, B) GLDH and C) CK 18 M30. D) Representative photomicrographs of liver tissue sections stained with hematoxylin \& eosin $(\mathrm{H} \& \mathrm{E}$; magnif. $\times 400$ magnification). Control rats that received vehicle only showed normal architecture of the hepatic lobule with normal histological structure of central vein and surrounding hepatocytes $(D ; C)$. The unirradiated rats received EPO at $5000 \mathrm{IU} / \mathrm{kg}$ showed preserved histological architecture (D; EPO). The livers from untreated irradiated rats $(R)$ demonstrated sever histological alterations, as represented by sever dilatation and congestion of central vein $(\leftrightarrow)$ associated with multiple numbers of newly formed bile ductules $(\rightarrow)$ as well as periductal fibrosis $(\longrightarrow)$ while the parenchyma showed degenerative change in the hepatocytes. EPO post exposure treatment improved the histological aberrations induced by radiation $(\mathrm{EPO}+\mathrm{R})$ as represented by subtle degree of vacuolar degeneration $(\longrightarrow)$ and moderately dilated central vein accompanied with milder degree of central vein congestion $(\leftrightarrow)$. Data are expressed 
as mean values \pm S.E.M. Statistical analysis was carried out using one way ANOVA followed by TukeyKramer multiple comparisons test, ${ }^{*} \mathbf{P}<0.05$ versus $(C), \# P<0.05$ versus $(R)$, and $@ P<0.05$ versus (EPO+ R).

Fig 7. Activation of hepatic and splenic $\alpha-7-$ nAChR protein expression mediated JAK-2/STAT-3 signaling stimulation contributed to the radiomitigative response and prevented MOD in EPO post- exposure treated irradiated rats. In survived rats, protein extracts $(30 \mu \mathrm{g})$ were separated 12\% SDS-PAGE. Representative western blot analysis, SDS- PAGE of A \& C) Hepatic and splenic JAK-2 (128 KDa), pJAK-2 (Tyr $\left.{ }^{1007 / 1008}\right)$ at $132 \mathrm{KDa}$, STAT-3 (90 KDa), p- STAT-3 $\left(\mathrm{Tyr}^{705}\right)$ at $86 \mathrm{KDa}$. E \& F) Hepatic and splenic $\alpha$-7- nAChR (54 KDa), and $\beta$-actin (42 KDa) as a housekeeping protein. B\& D) Fold change in hepatic and splenic JAK-2, p- JAK-2, STAT-3 and p- STAT-3 protein expression normalized to $\beta$-actin. G) Fold change in hepatic and splenic $\alpha-7-n A C h R$ protein expression normalized to $\beta$-actin. Data are expressed as mean values \pm S.E.M. Statistical analysis was carried out using one way ANOVA followed by Tukey- Kramer multiple comparisons test, ${ }^{*} \mathbf{P}<0.05$ versus $(C), \# \mathbf{P}<0.05$ versus $(\mathrm{R})$, and $@ \mathbf{P}<0.05$ versus $(\mathbf{E P O}+\mathbf{R})$.

Fig 8. Up-regulation of hepatic and splenic Nrf-2/HO-1 cascade in EPO post- exposure treated irradiated rats. Relative gene expression of Nrf-2 and HO-1 was detected by RT-PCR and quantified by scanning densitometric analysis and normalized to the housekeeping gene $\beta$-actin mRNA expression. Data are expressed as mean values \pm S.E.M. Statistical analysis was carried out using one way ANOVA followed by Tukey- Kramer multiple comparisons test, ${ }^{*} \mathbf{P}<0.05$ versus $(C), \# P<0.05$ versus $(\mathrm{R})$, and $@ \mathbf{P}<0.05$ versus $(\mathbf{E P O}+\mathbf{R})$.

Fig 9. EPO post- exposure treatment abrogates oxidative stress via enhancing Nrf-2 driven phase II antioxidant enzymes and restoring arginase activity. A) Relative gene expression of NQO-1 and TRXR-1 was detected by RT-PCR and quantified by scanning densitometric analysis and normalized to the housekeeping gene $\beta$-actin mRNA expression. B) hepatic and splenic MDA level, C) hepatic and splenic NO level, D) hepatic and splenic arginase activity and E) serum IL-10 level. F) Representative photomicrographs of spleen tissue sections stained with hematoxylin \& eosin (H\&E; magnif. $\times 400$ magnification). Spleen of control rats showed normal white \&red pulps, vascular organization and cellular composition (C). In EPO group, spleen sections showed preserved splenic architecture coupled with intact white and red pulps (EPO). While, spleen of untreated irradiated rats (R) revealed sever pathological alterations as represented by decrease in erythroid and myeloid cell populations and replaced by stromal cells (depopulation) $(\rightarrow$ ) associated with congested blood vessels $(B V)(\leftrightarrow)$. In spleen of EPO+ R group, lymphoid hyperplasia (LH) of white pulp was noticed coupled with restoration of 
erythroid and myeloid cells in the red pulp $(\rightarrow)$ with absence of blood vessels congestion. Data are expressed as mean values \pm S.E.M. Statistical analysis was carried out using one way ANOVA followed by Tukey- Kramer multiple comparisons test, ${ }^{*} \mathbf{P}<0.05$ versus $(C), \# P<0.05$ versus (R), and @ $P<0.05$ versus (EPO+ R).

Fig 10. EPO post- exposure treatment suppresses hepatic and splenic Bax, p53 and caspase-3 as well as reinstates Bcl-2 expression in TBI rats. A) Relative gene expression of Bax, Bcl-2 and p53 was detected by RT-PCR and quantified by scanning densitometric analysis and normalized to the housekeeping gene $\beta$ actin mRNA expression. B) Bax/Bcl-2 ratio and C) Fold change in caspase activity. Data are expressed as mean values \pm S.E.M. Statistical analysis was carried out using one way ANOVA followed by TukeyKramer multiple comparisons test, ${ }^{*} \mathrm{P}<0.05$ versus $(\mathrm{C}), \# \mathrm{P}<0.05$ versus $(\mathrm{R})$, and $@ \mathrm{P}<0.05$ versus (EPO+ R). 
Table 1. Primer sequences used for reverse transcription PCR.

\begin{tabular}{lll}
\hline Target gene & \multicolumn{1}{c}{$\begin{array}{c}\text { Oligonucleotide sequence } \\
\text { Sense }\left(5^{\prime}-3^{\prime}\right)\end{array}$} & \multicolumn{1}{c}{$\begin{array}{c}\text { Oligonucleotide sequence } \\
\text { antisense }\left(5^{\prime}-3^{\prime}\right)\end{array}$} \\
\hline Nrf-2 & AGCAGGACTGGAGAAGTT & TTCTTTTCCAGCGAGGAGA \\
HO-1 & CCTCACTGGCAGGAAATCATC & CCTCGTGGAGACGCTTTACATA \\
NQO-1 & AGCCCAGATATTGTGGCCG & CCTTTCAGAATGGCTGGCAC \\
TRXR-1 & ACTGCTCAATCCACAAACAGC & CCACGGTCTCTAAGCCAATAGT \\
Bax & GTTGCCCTCTTCTACTTTG & AGCCACCCTGGTCTTG \\
Bcl-2 & CGGGAGAACAGGGTATGA & CAGGCTGGAAGGAGAAGAT \\
P53 & GTTCCGAGAGCTGAATGAGG & TTTTATGGCGGGACGTAGAC \\
$\beta$ - actin & TGCTGGTGCTGAGTATGTCG & TTGAGAGCAATGCCAGCC \\
\hline
\end{tabular}


Fig 1.

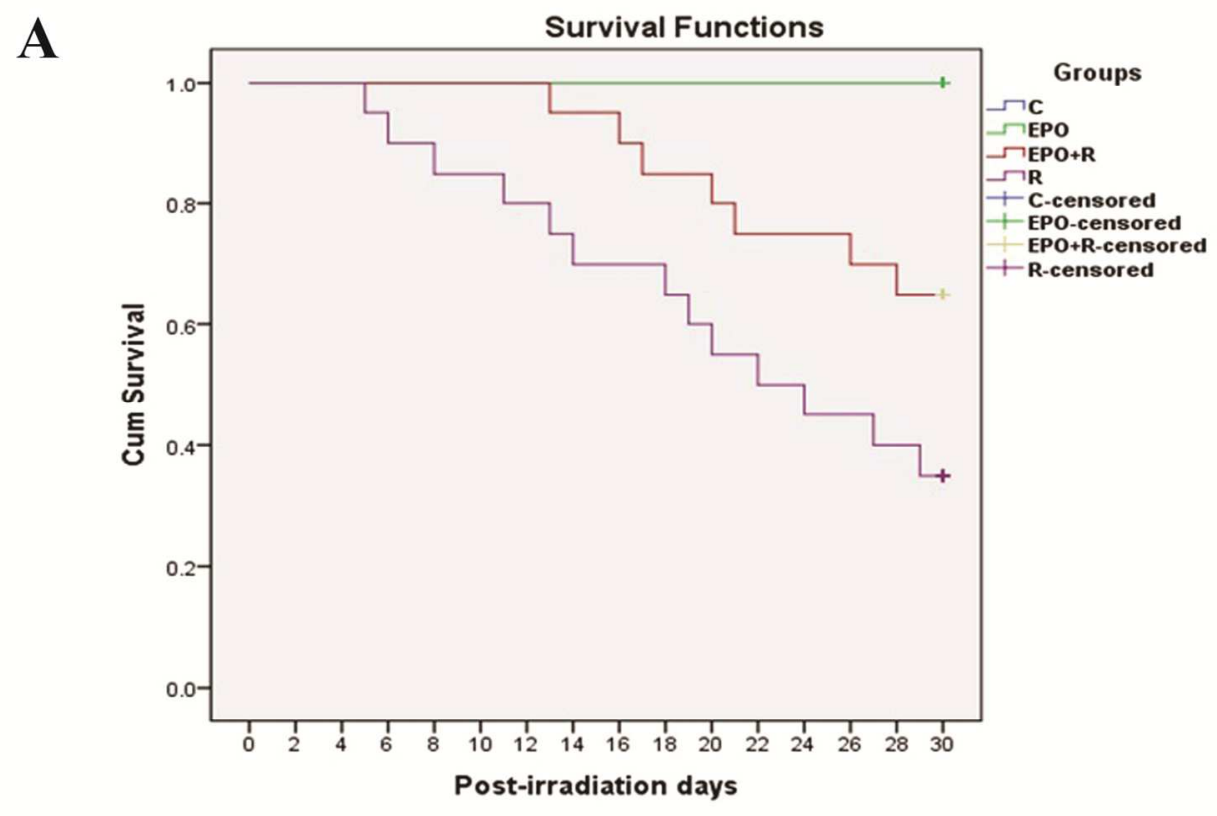

\section{B}

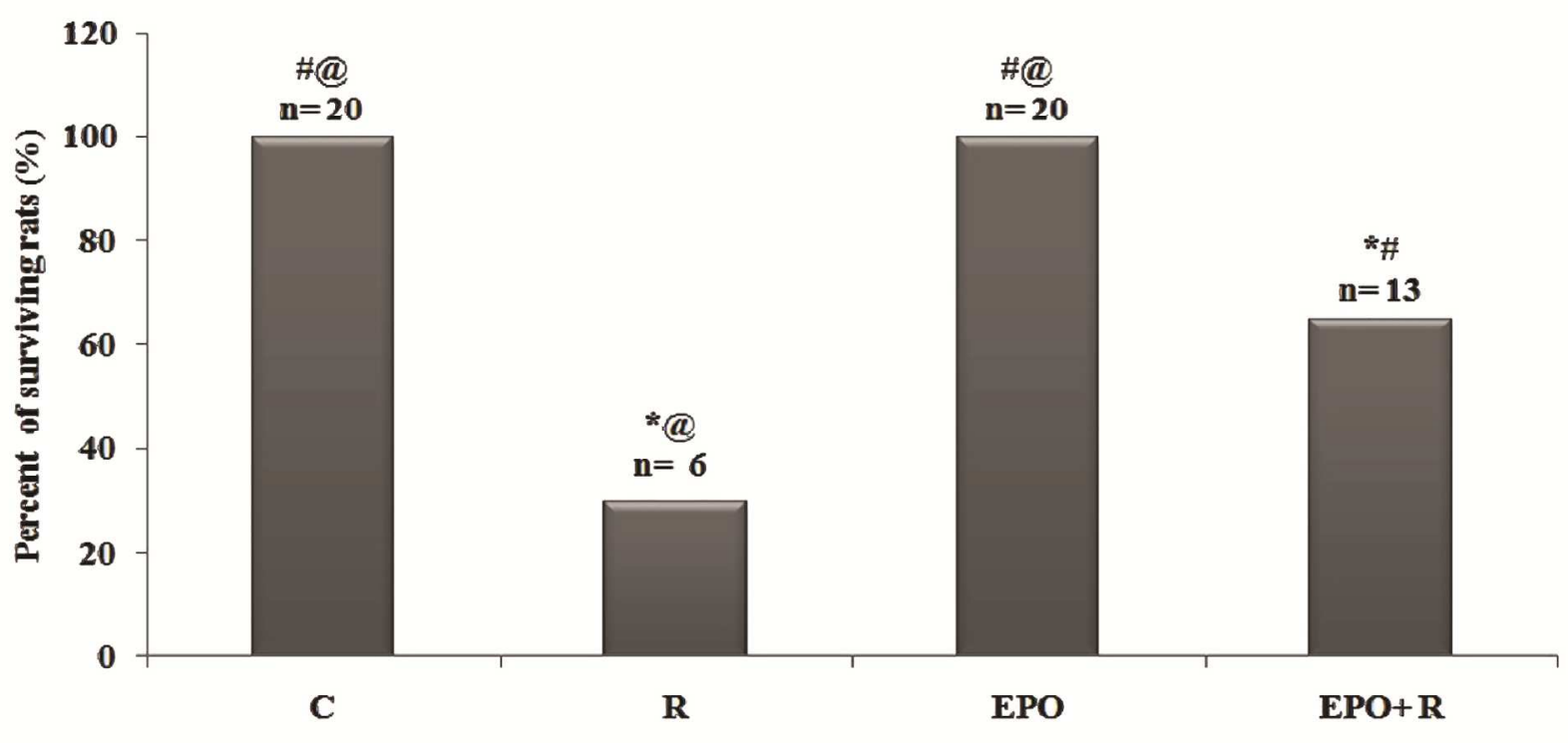


Fig 2.
A
B
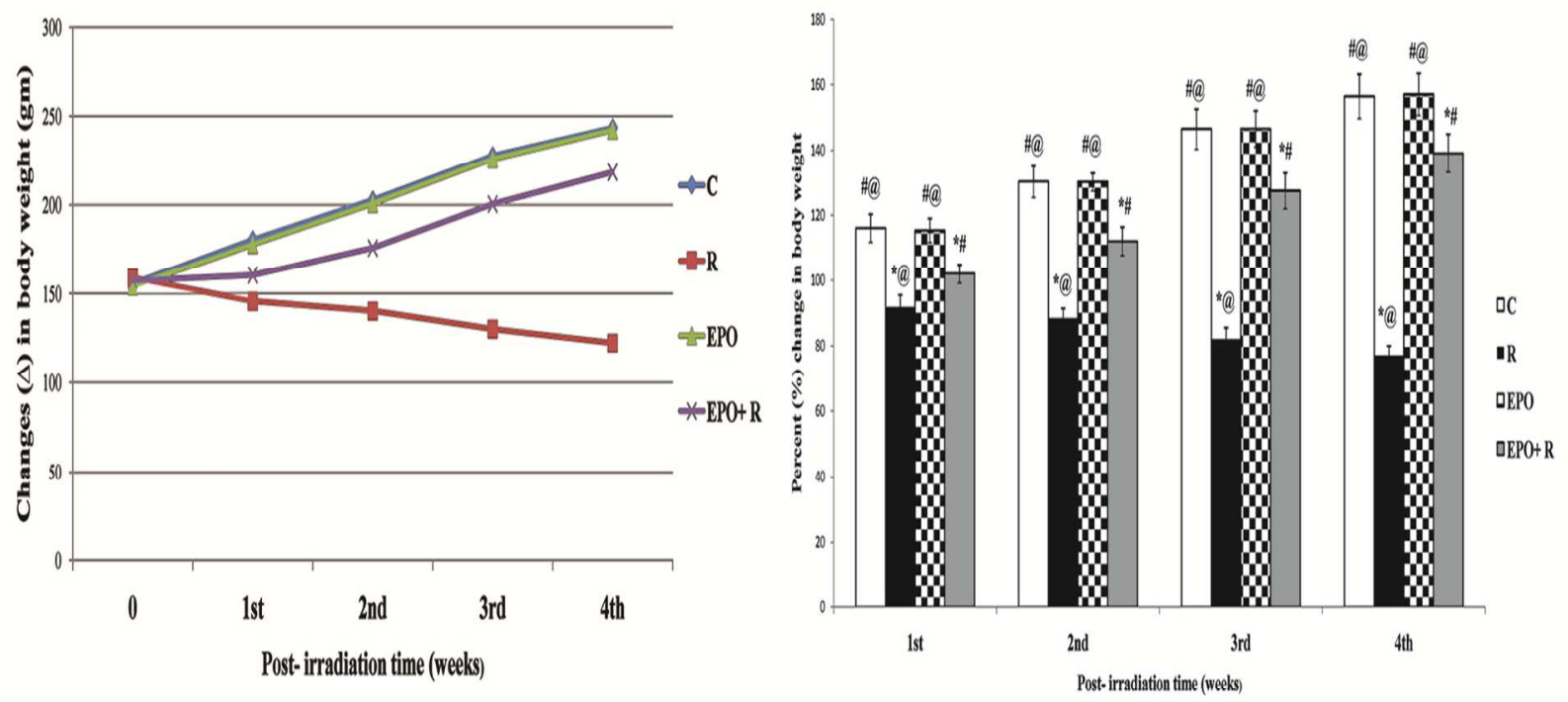

C
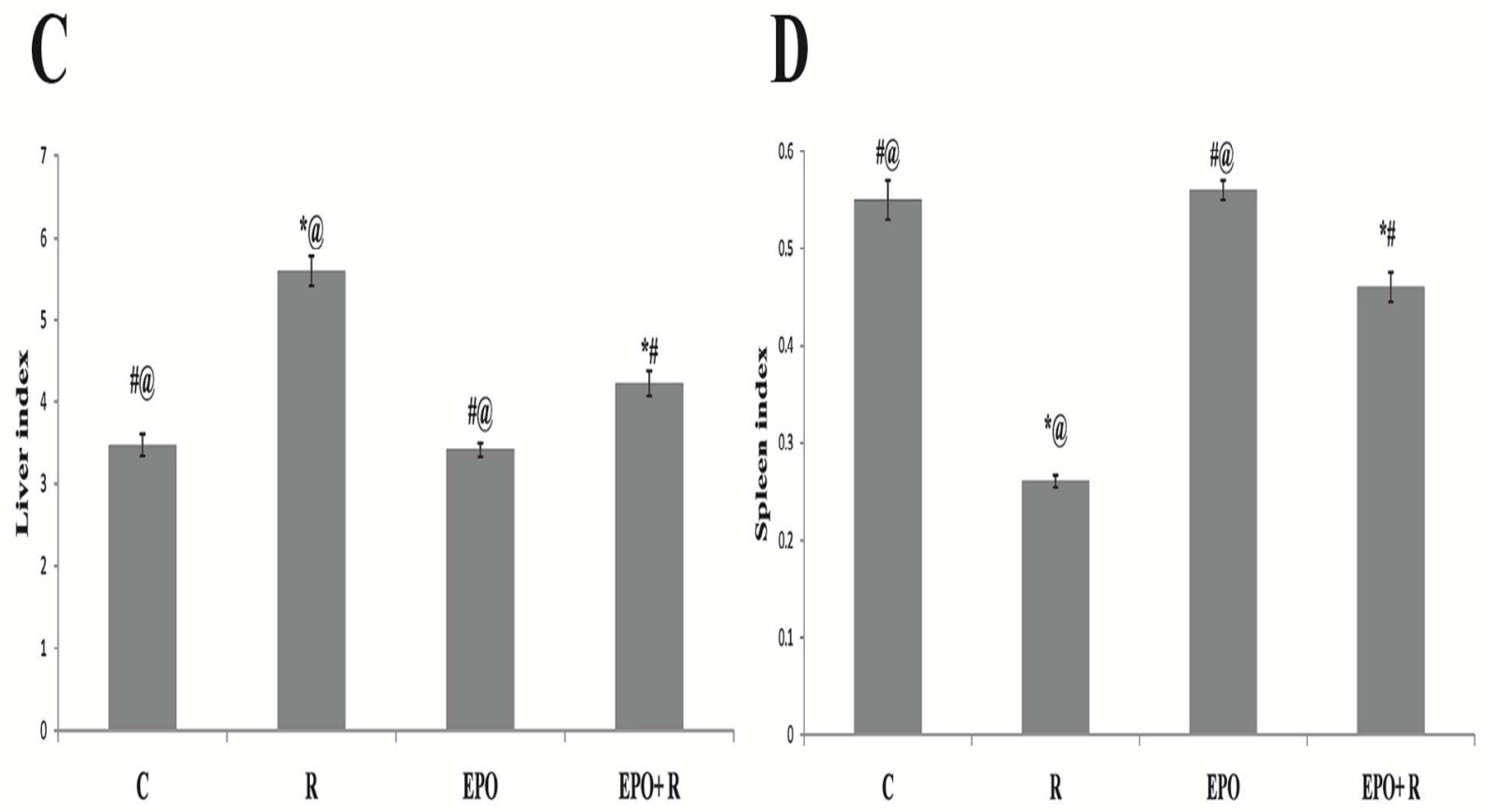
Fig 3.

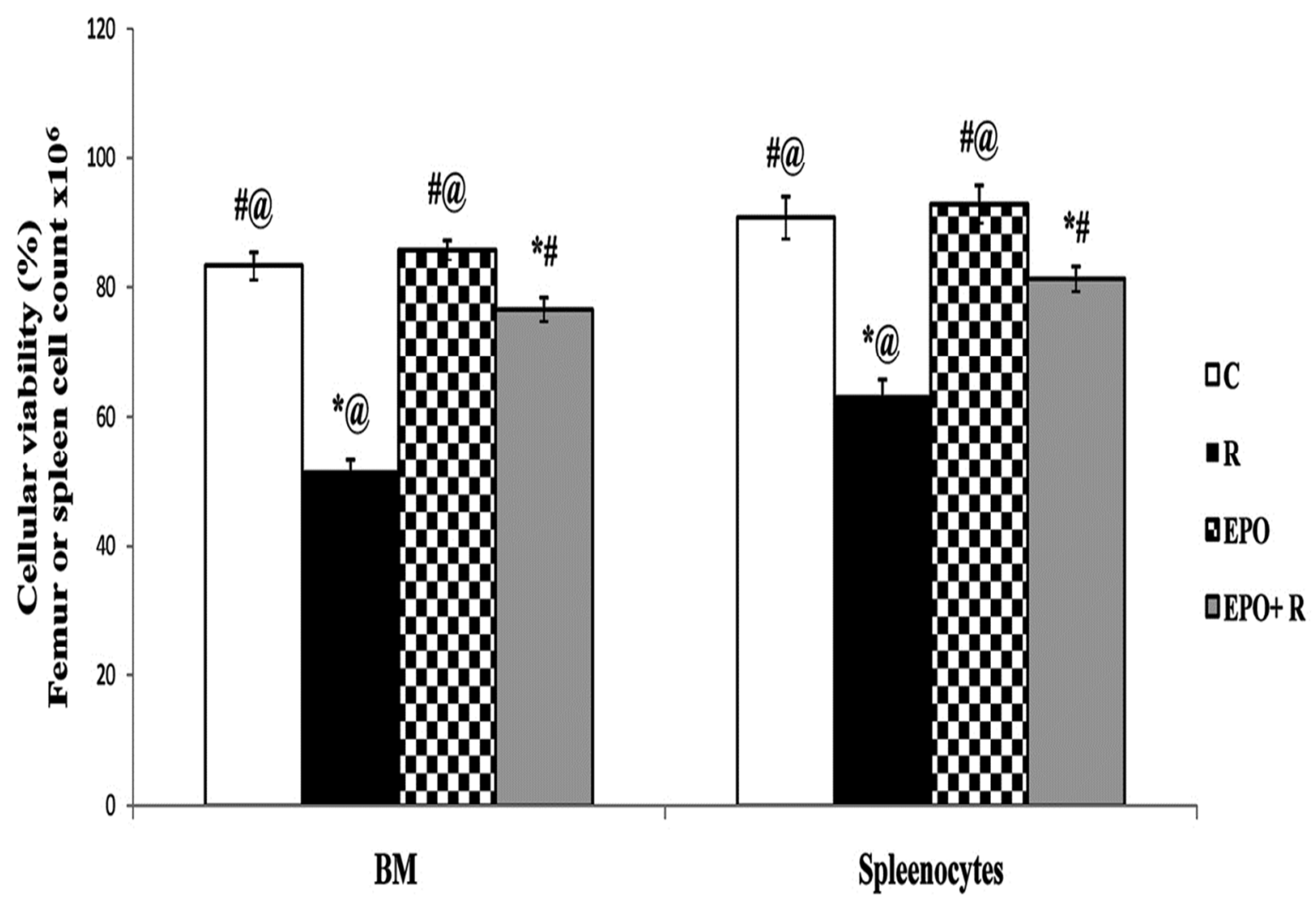


Fig 4.

A B
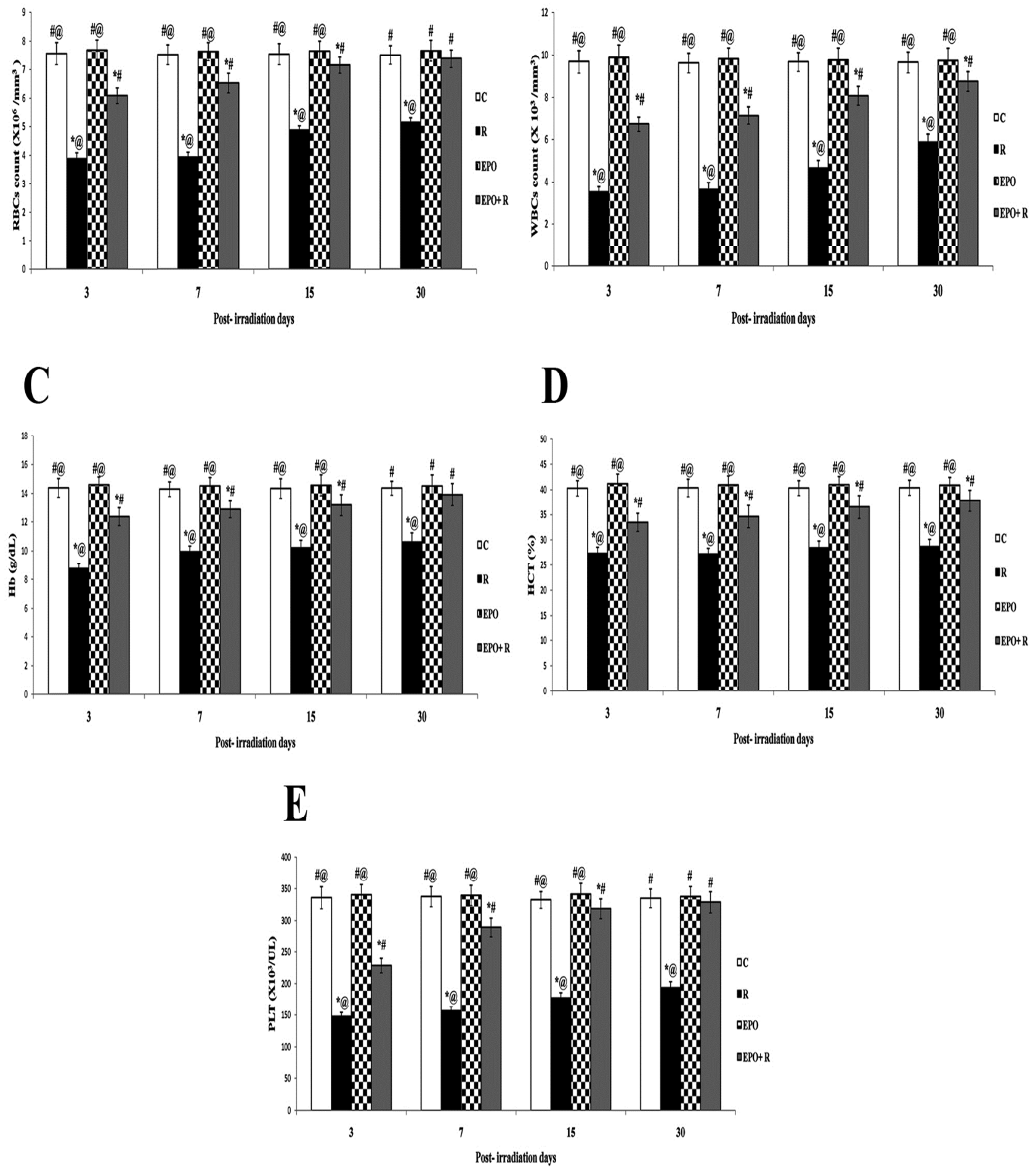
Fig 5.
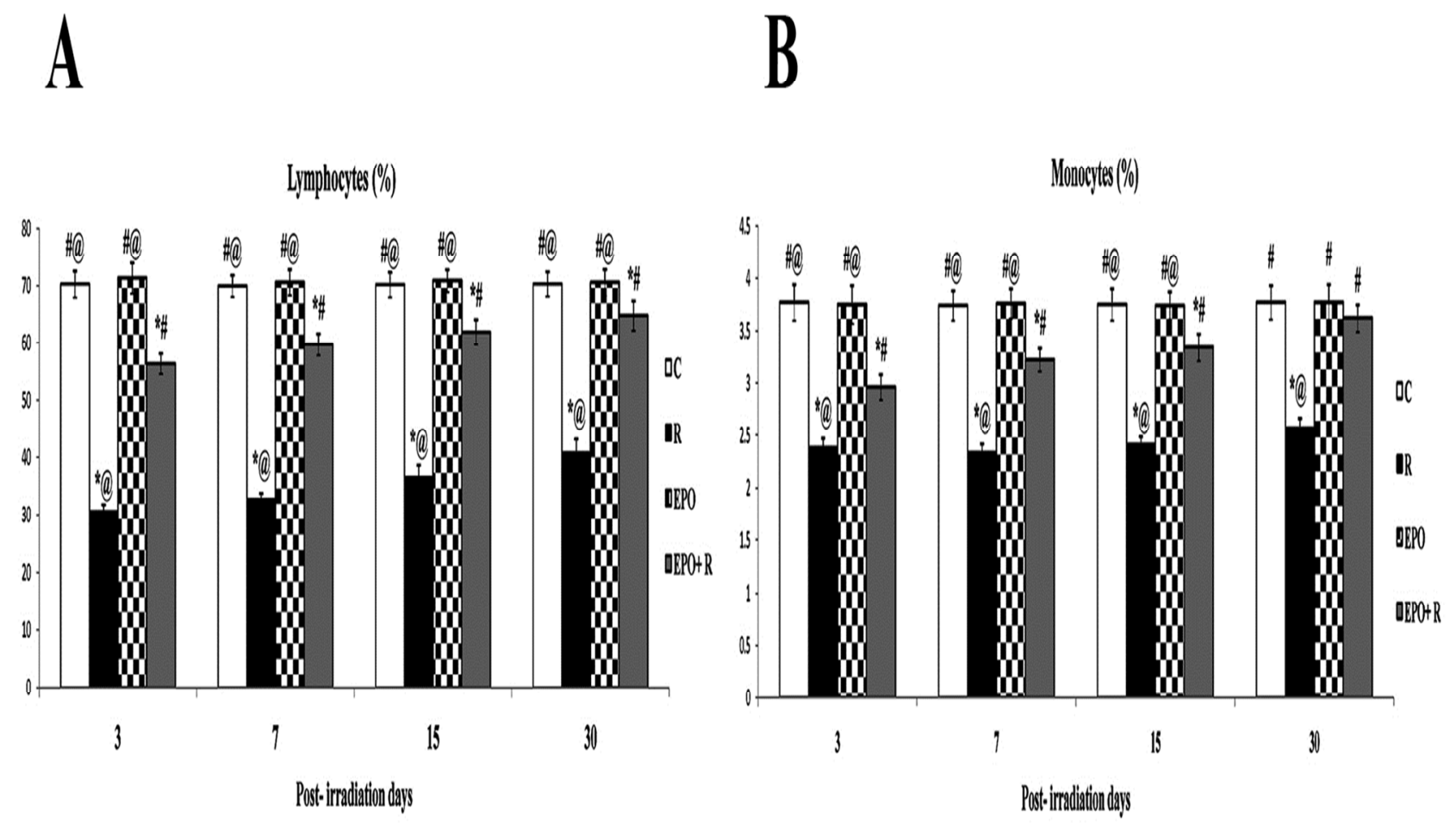

C

D

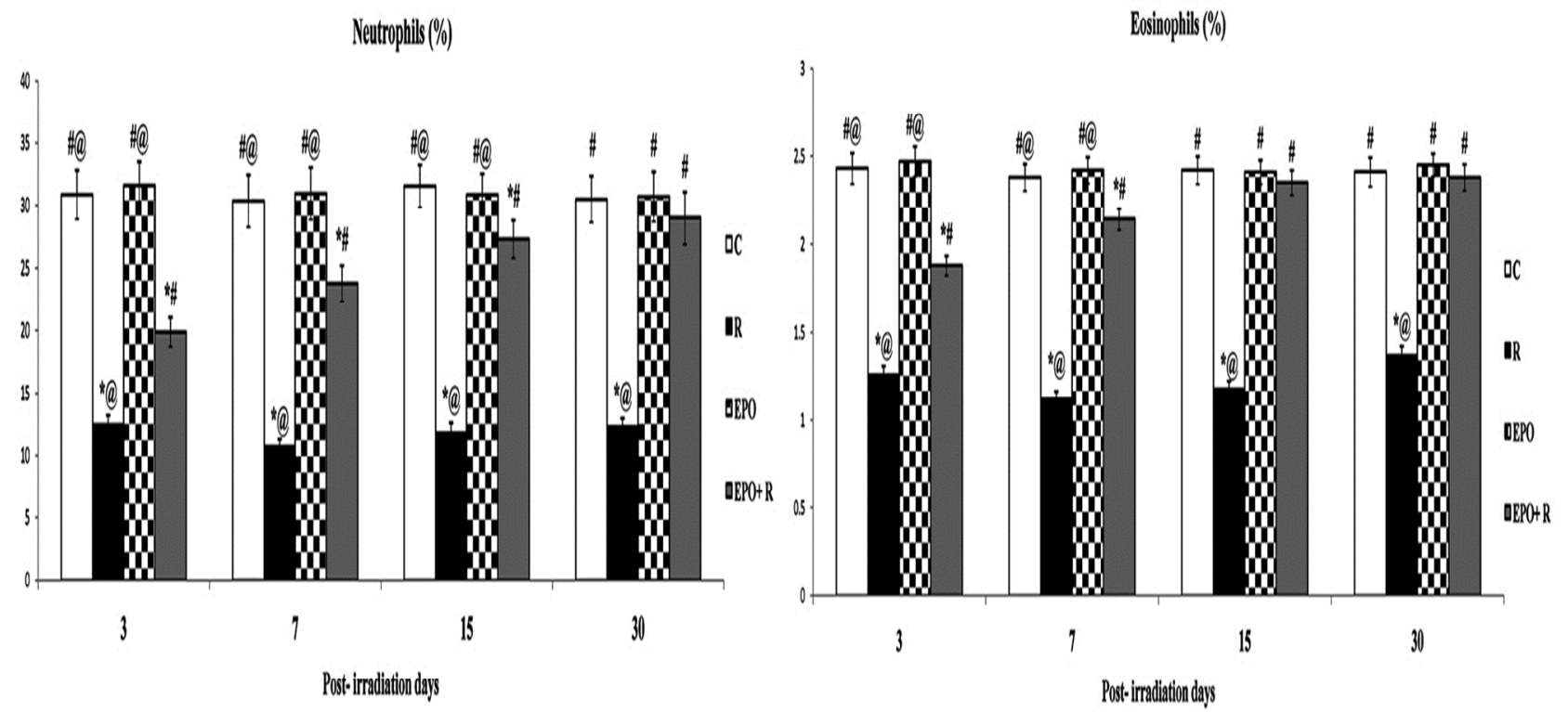


Fig 6.

A

B
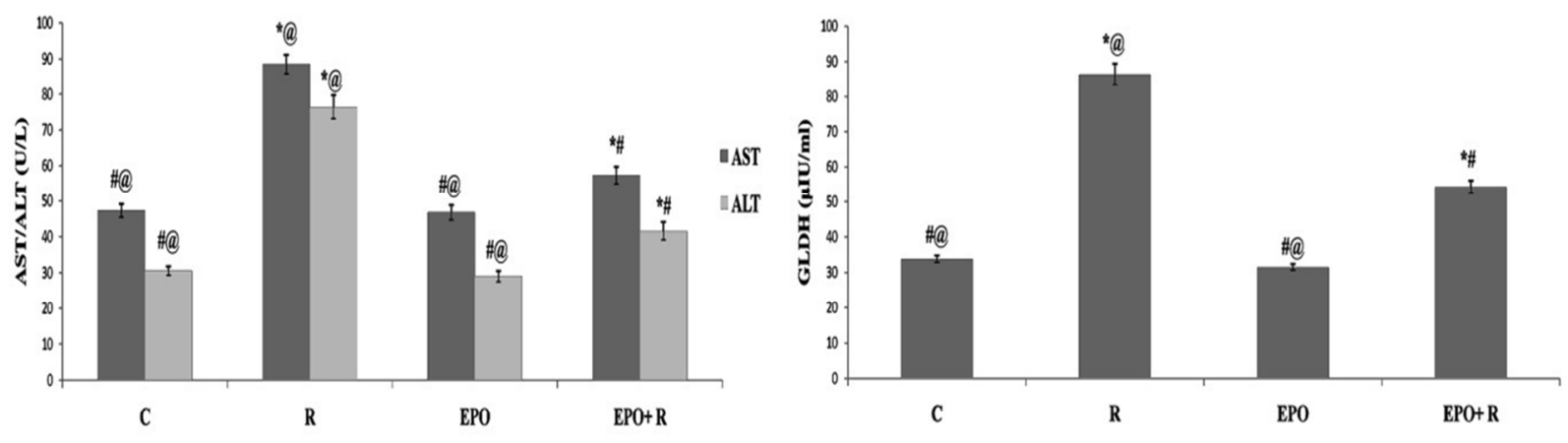

C

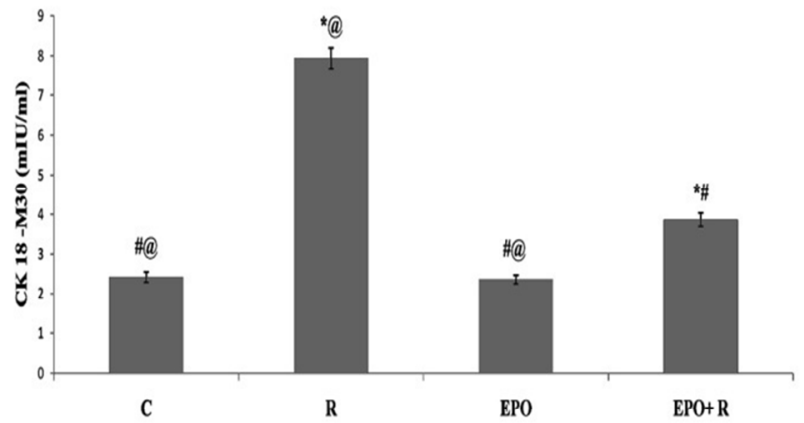

D

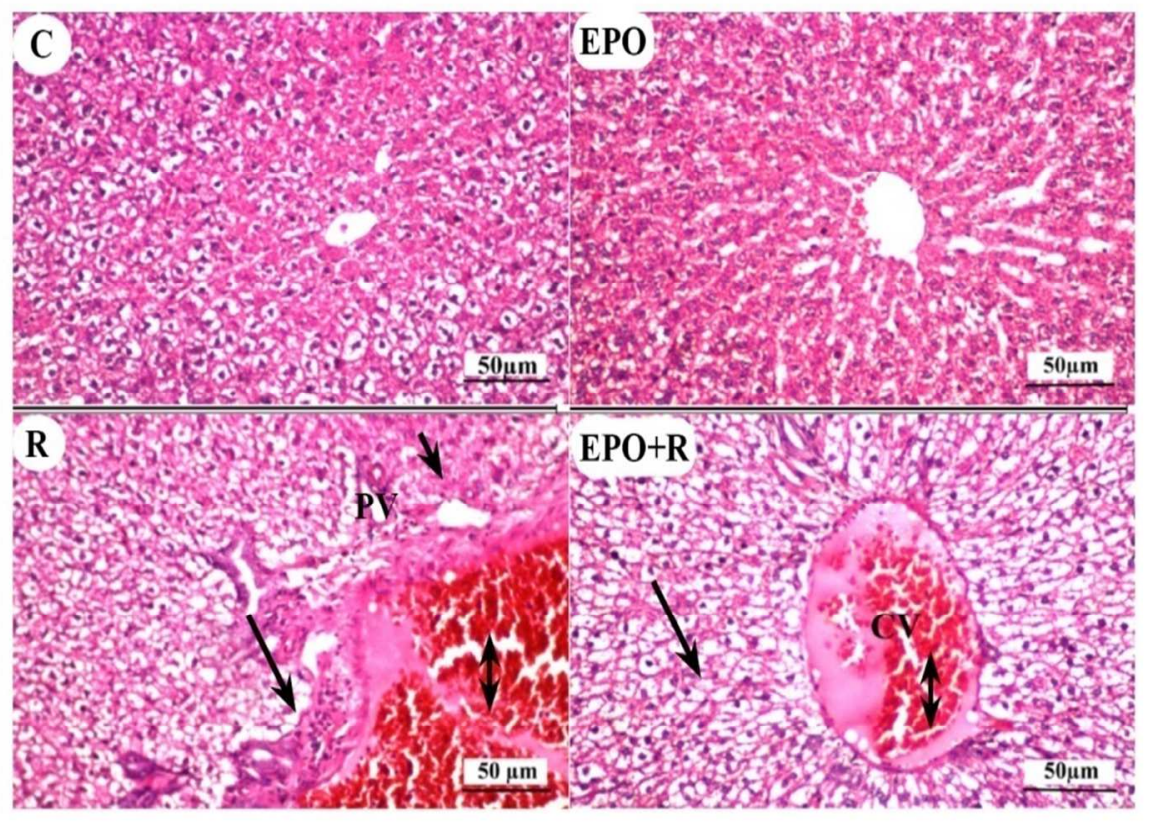


Fig 7.

A
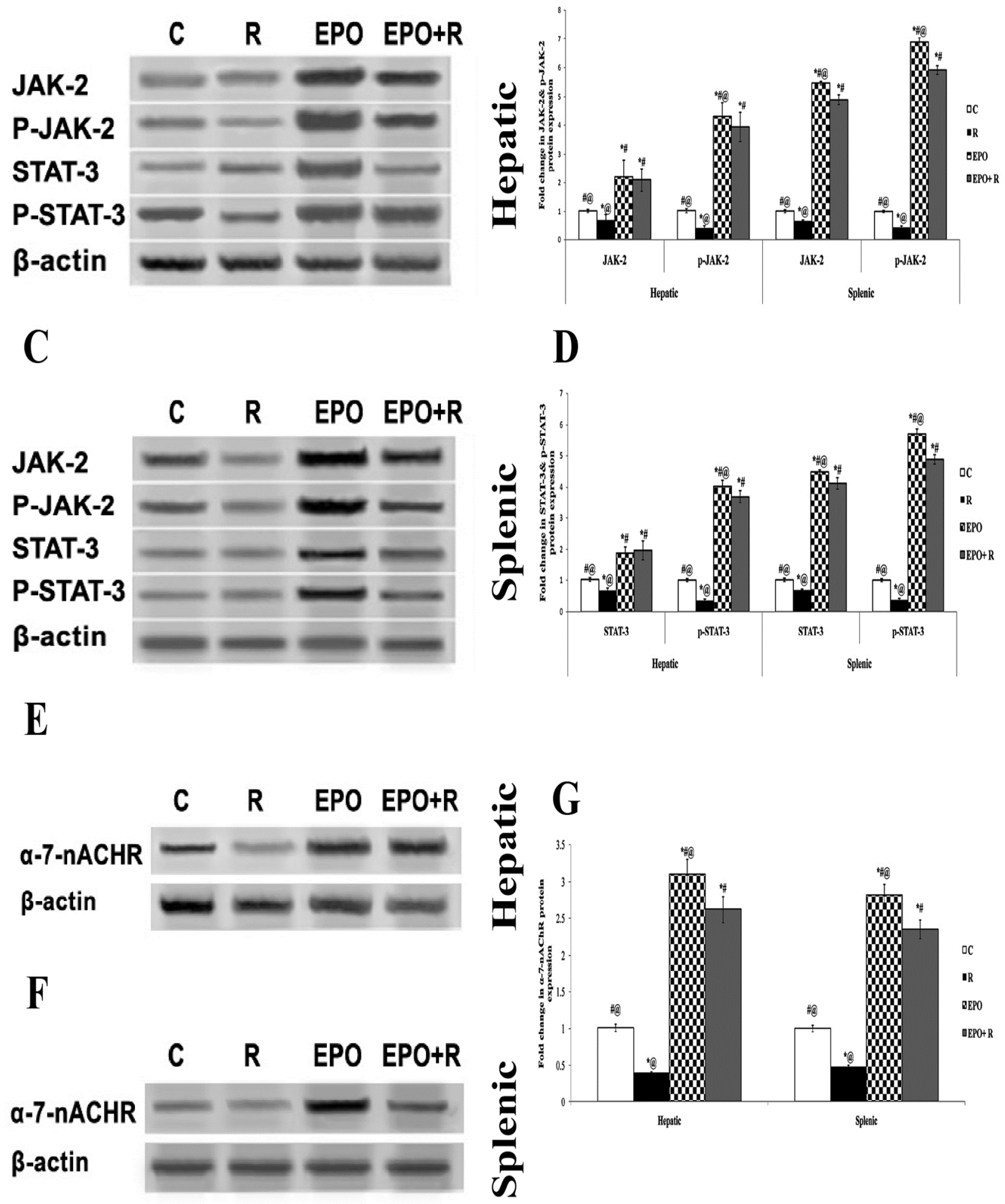
Fig 8.

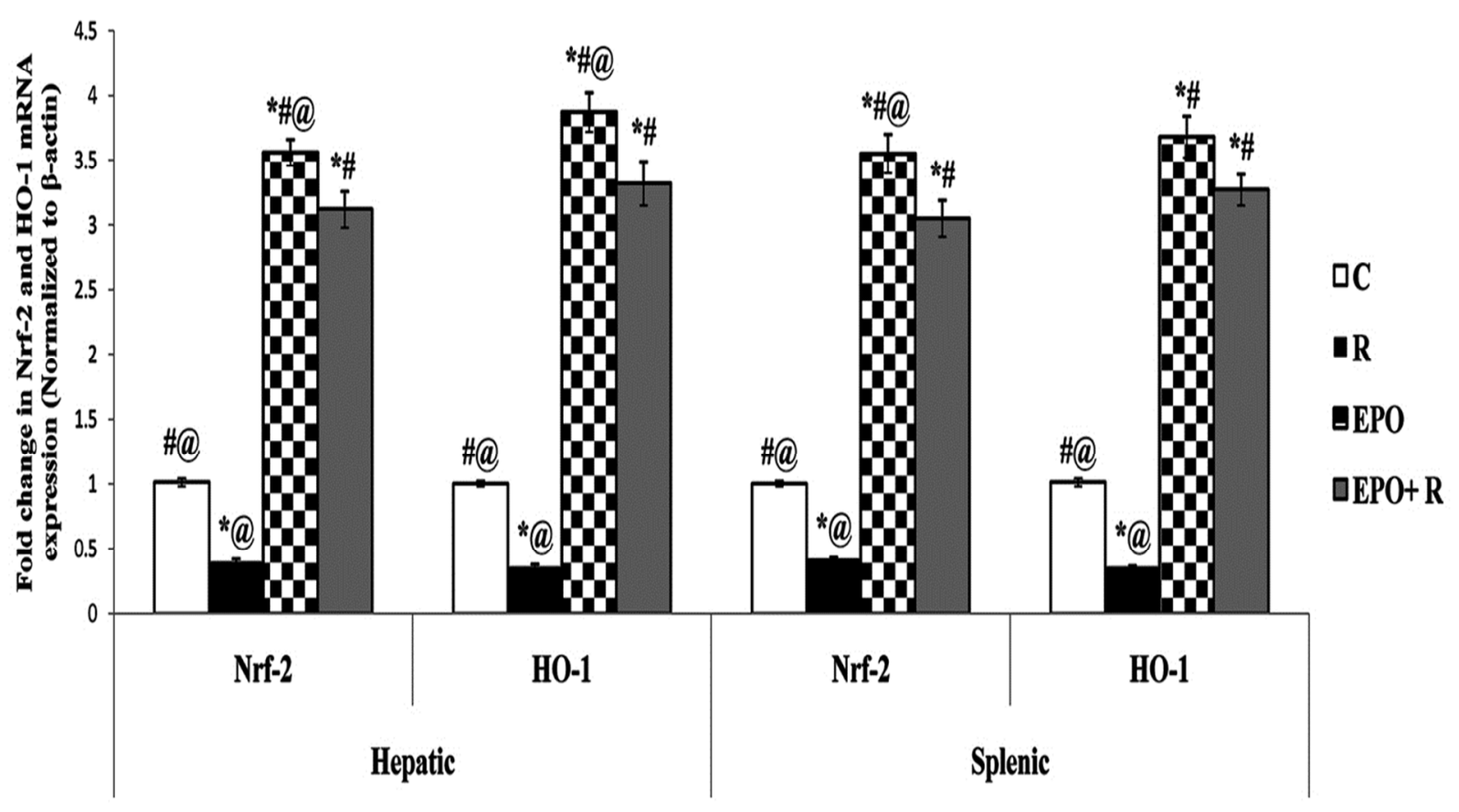


Fig 9.
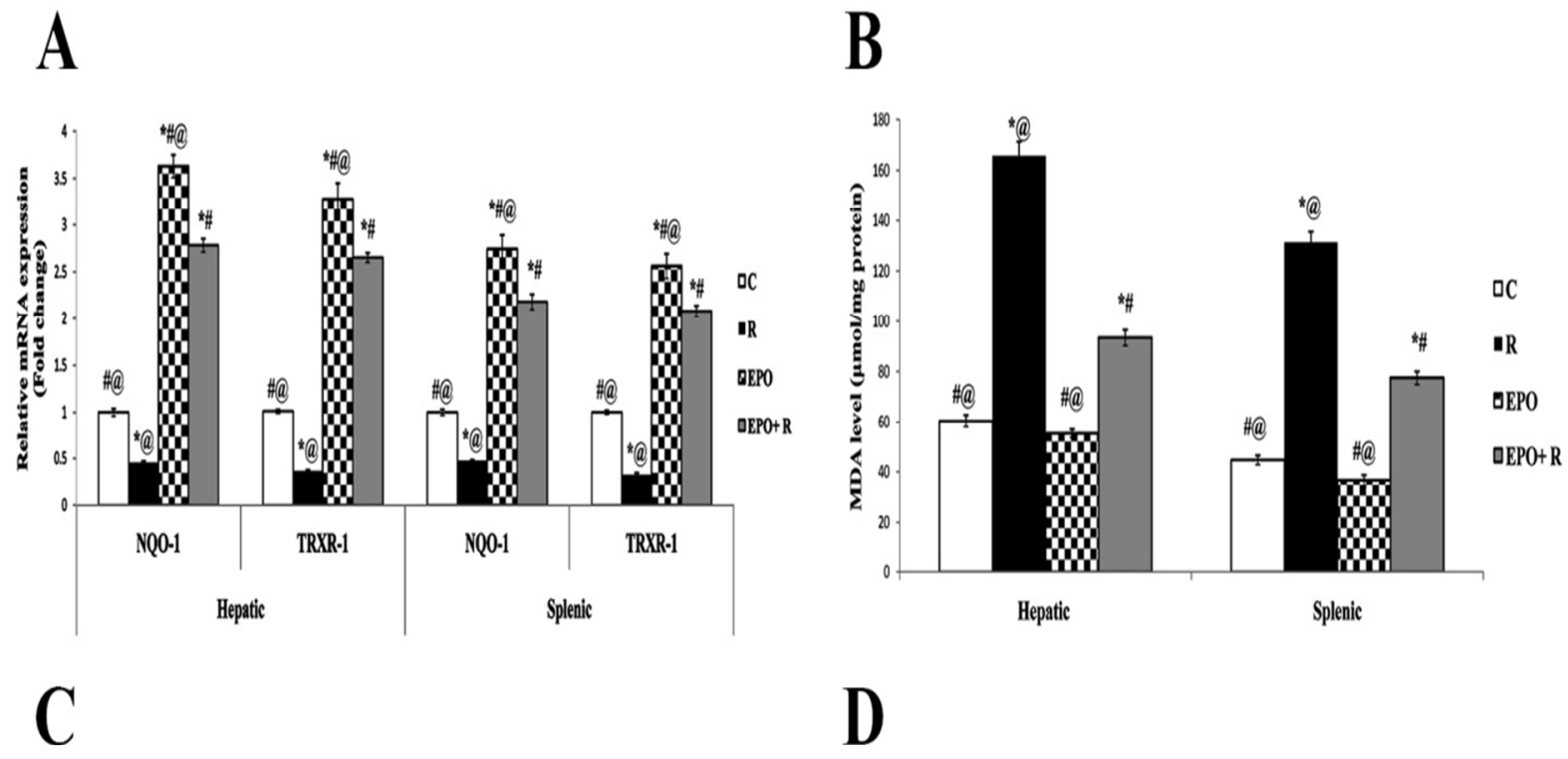

D
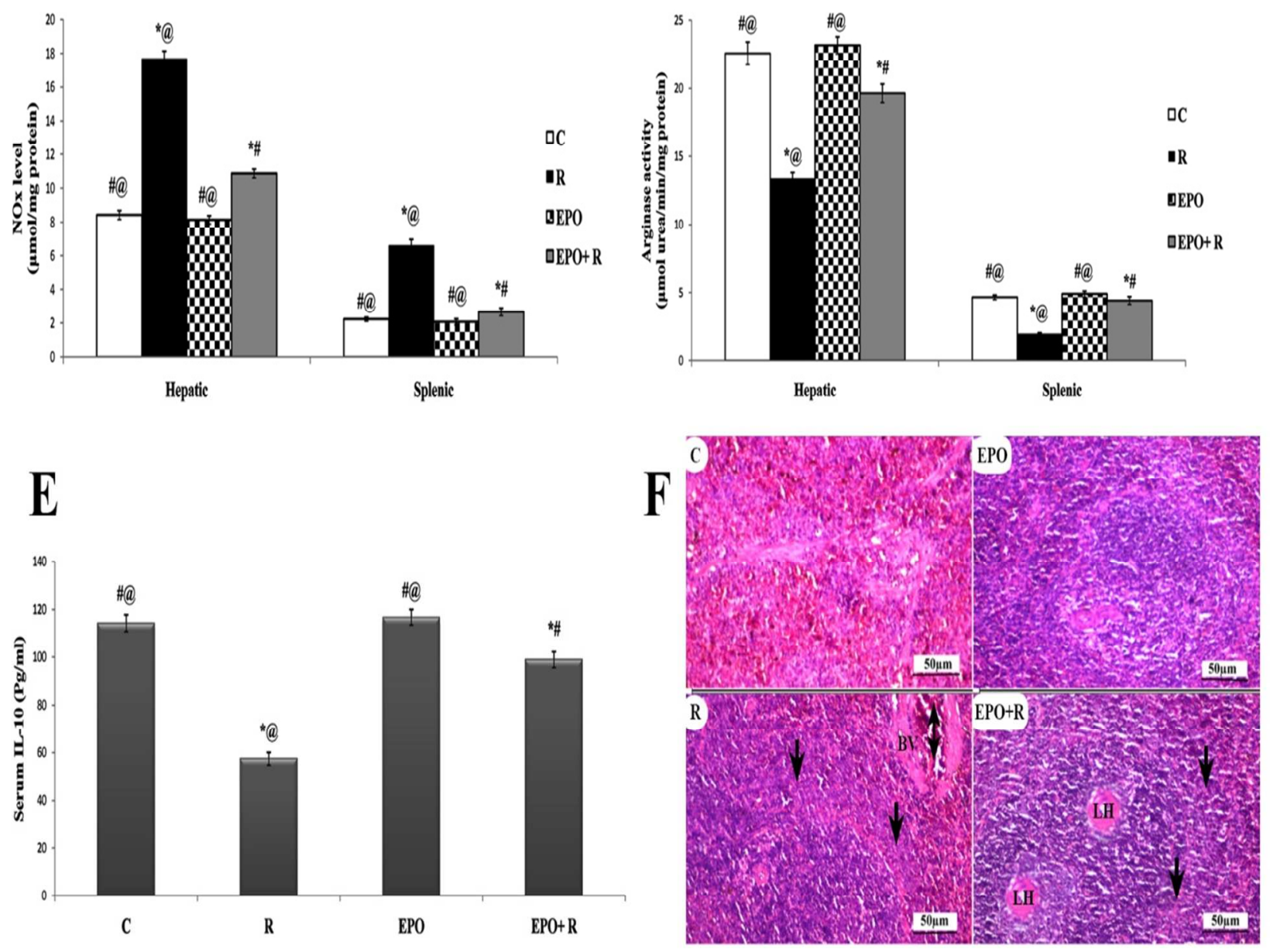
Fig 10.

A

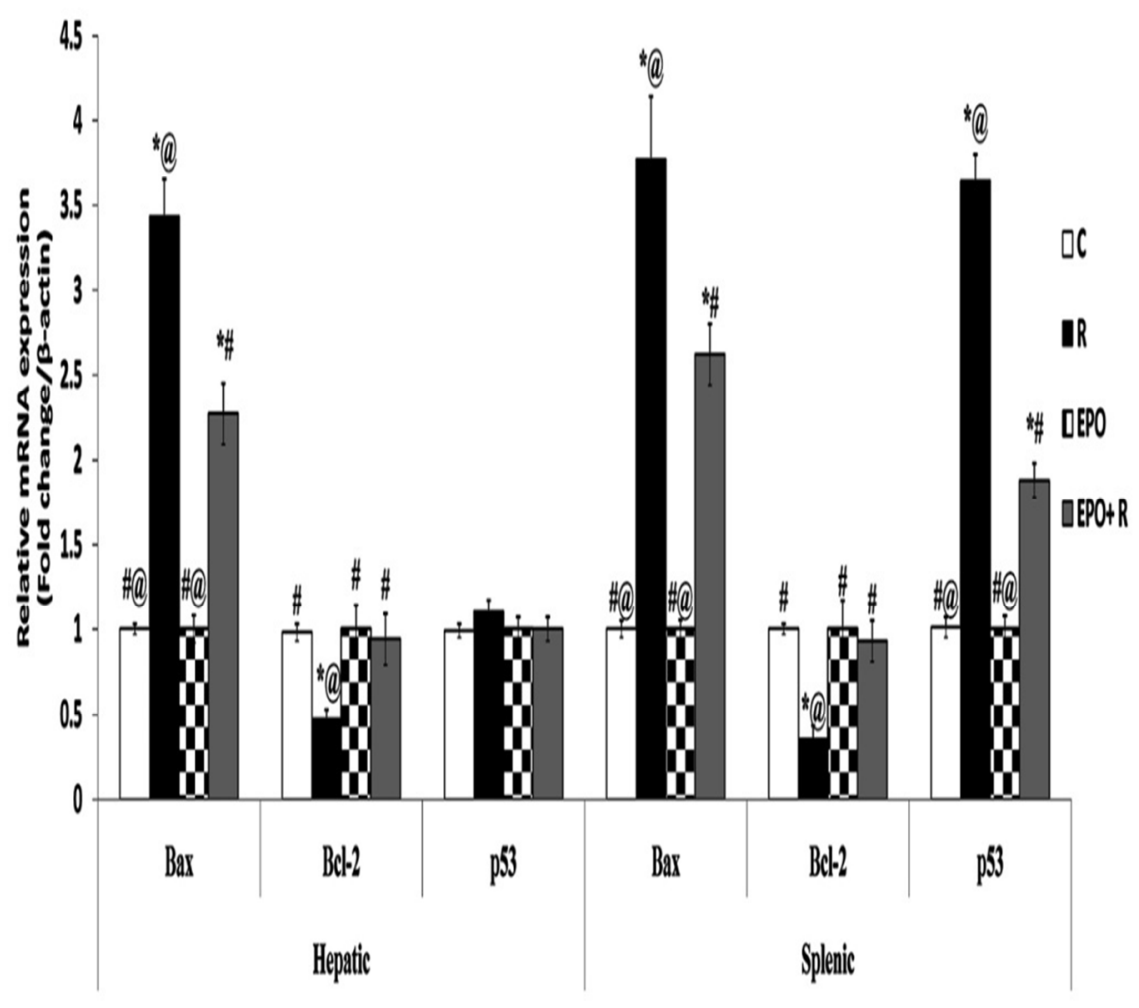

B<smiles></smiles>

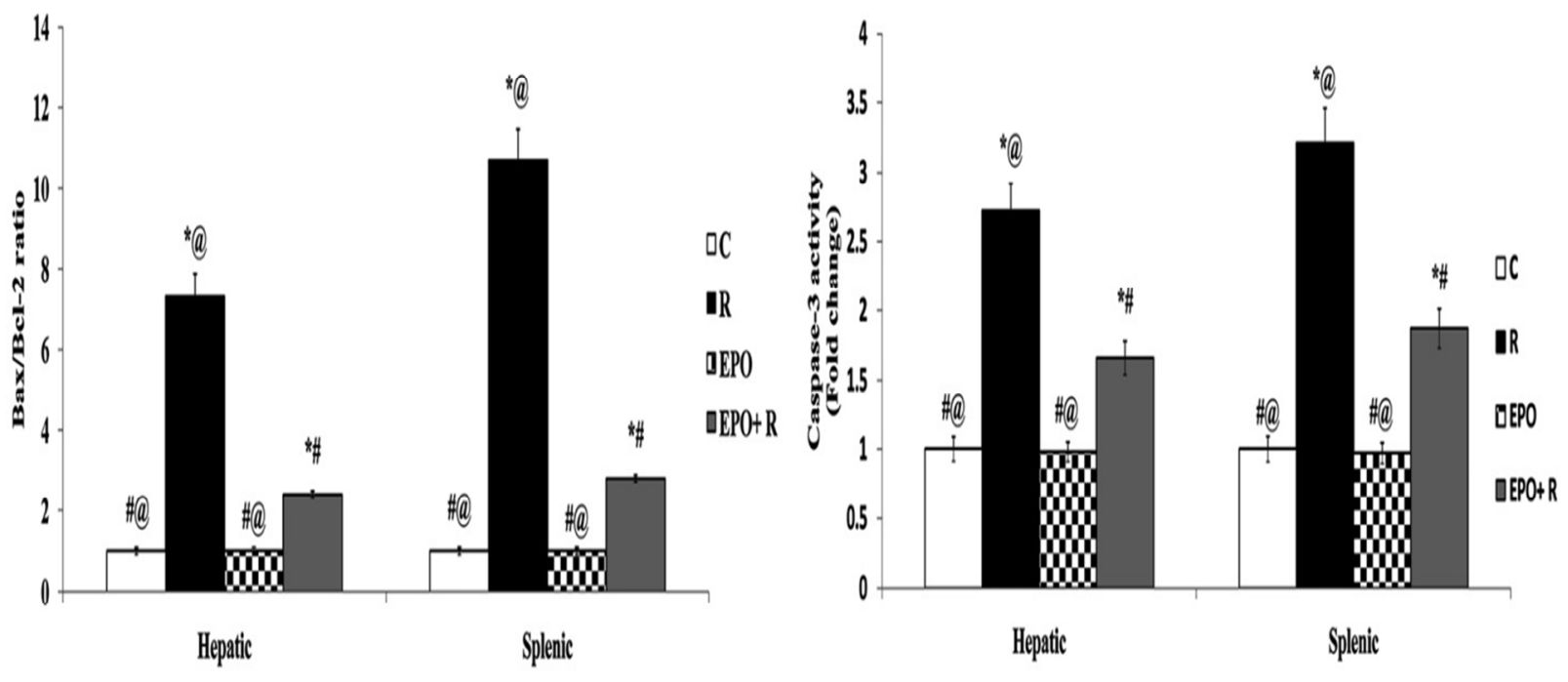

